\title{
The cytoskeleton in spermatogenesis
}

\author{
Jessica E M Dunleavy¹, Moira K O’Bryan¹, Peter G Stanton² and Liza O'Donnell² \\ ${ }^{1}$ The School of Biological Sciences, Monash University, Clayton, Victoria, Australia and ${ }^{2}$ Centre for Reproductive \\ Health, Hudson Institute of Medical Research and Monash University, Clayton, Victoria, Australia
}

Correspondence should be addressed to J E M Dunleavy; Email: Jessica.dunleavy@monash.edu

\begin{abstract}
As germ cells progress through spermatogenesis, they undergo a dramatic transformation, wherein a single, diploid spermatogonial stem cell ultimately produces thousands of highly specialised, haploid spermatozoa. The cytoskeleton is an integral aspect of all eukaryotic cells. It concomitantly provides both structural support and functional pliability, performing key roles in many fundamental processes including, motility, intracellular trafficking, differentiation and cell division. Accordingly, cytoskeletal dynamics underlie many key spermatogenic processes. This review summarises the organisational and functional aspects of the four major cytoskeletal components (actin, microtubules, intermediate filaments and septins) during the various spermatogenic phases in mammals. We focus on the cytoskeletal machinery of both germ cells and Sertoli cells, and thus, highlight the critical importance of a dynamic and precisely regulated cytoskeleton for male fertility.

Reproduction (2019) 157 R53-R72
\end{abstract}

\section{Introduction}

Spermatogenesis is a complex process, involving the synchronous production of vast numbers of genetically distinct, haploid spermatozoa capable of surviving and traversing the female reproductive tract. In mammals, the process is spatially restricted to the seminiferous tubules of the testis, wherein germ cells develop in a stratified epithelium.

The spermatogenic cycle initiates with spermatogonial stem cells (SSCs) undergoing mitosis to both renew their own population and to provide cells that become terminally committed to further differentiation. Differentiating spermatogonia subsequently undergo transitamplification, progressing through multiple mitotic divisions, before ultimately entering meiosis. During meiosis, chromosomes are duplicated and undergo homologous recombination to generate genetically diverse tetraploid spermatocytes. Two rapid divisions follow, resulting in the production of haploid round spermatids. During spermiogenesis, round spermatids are then remodelled into streamlined spermatozoa with an acrosome (required for fertilisation) and a flagellum (required for motility), in addition to gaining a speciesspecific head shape. As germ cells progress through each phase, they are translocated from the base of the seminiferous epithelium to the luminal edge. At the end of spermatogenesis, spermatozoa are released into the lumen via a series of processes collectively called spermiation.

Sertoli cells, the somatic cells of the seminiferous epithelium, provide structural and nutritional support throughout spermatogenesis and directly facilitate germ cell translocation within the epithelium, as well as spermiation. Fundamentally, spermatogenesis involves numerous germ cell divisions and dramatic changes in both germ and Sertoli cell morphology. Cytoskeletal elements are an integral aspect of these processes and are thus essential for male fertility.

The eukaryotic cytoskeleton is defined as being composed of actin filaments (microfilaments; Box 1), microtubules (Box 2), intermediate filaments ((Box 3), and, in more contemporary definitions, septin proteins (Mostowy \& Cossart 2012; Box 4). Each of these elements is fundamental to eukaryotic cell biology and, as a collective, are integral for a diversity of cellular functions, including division, motility, differentiation, migration, adhesion and intracellular trafficking.

This review will focus on the organisation and function of the mammalian germ cell cytoskeleton during the various spermatogenic phases, in addition to addressing the roles of the Sertoli cell cytoskeleton.

\section{Cytoskeletal changes during germ cell development}

\section{Spermatogonia and spermatocytes}

As is well established for all mammalian cell division, the mitotic and meiotic divisions of spermatogenesis are directly facilitated by the cytoskeleton and many cytoskeletal aspects are generic. Microtubules form the typical machinery of the mitotic bipolar spindle apparatus and the midbody, while F-actin and septins 


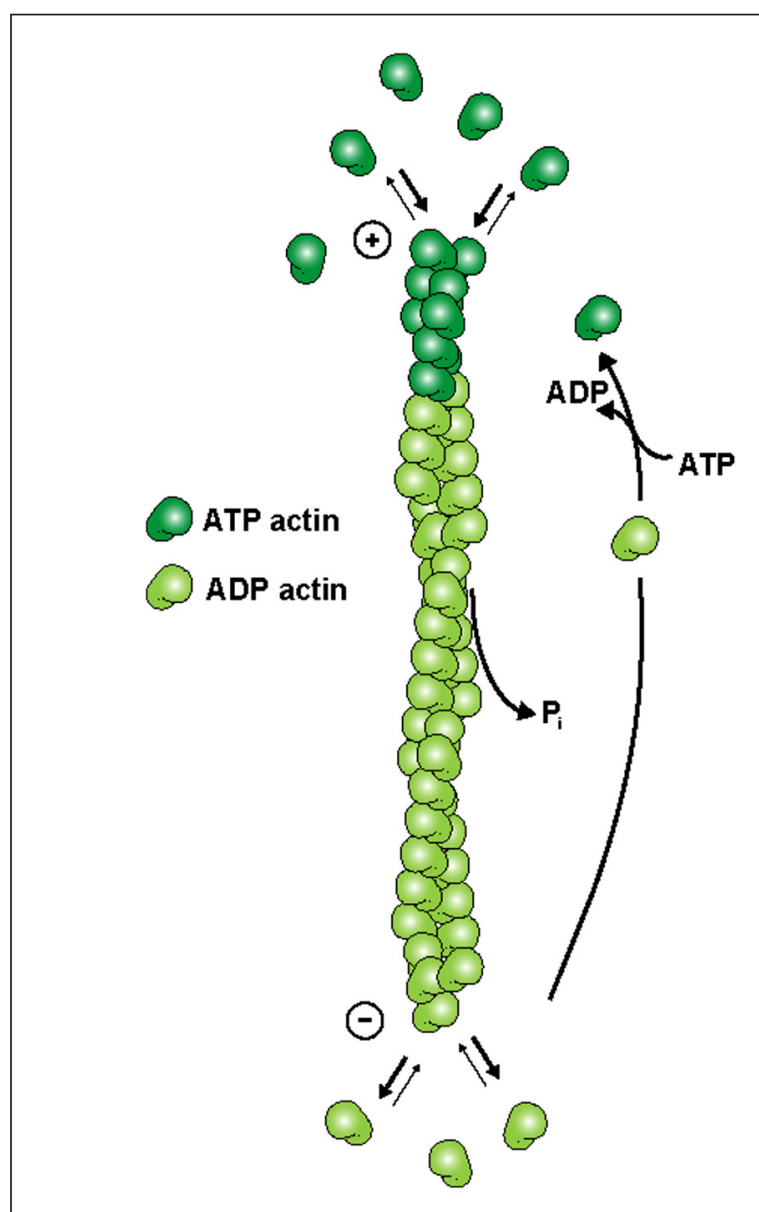

Box 1 Actin schematic.

\section{Actin}

Filamentous actin (F-actin) exists as a two-chained, helical polymer with a diameter of $\sim 7 \mathrm{~nm}$. It is formed by the ATP-dependent polymerisation of monomeric or 'globular' actin (G-actin) and new filament formation is typically driven by an actin-nucleating protein, such as ARP2/3, various formins or tandem-monomer-binding nucleators (Pollard 2016). Due to monomer orientation within the filament, F-actin is intrinsically polarised with a fast-growing plus-end known as the 'barbed-end' and a minus-end, which exhibits slower dynamics, known as the 'pointed-end' (Pollard 2016). The basic F-actin polymer is used to generate dynamic cytoskeletal networks, consisting of multiple cross-linked and/or branched actin filaments. Such networks provide mechanical support within the cell, facilitate organelle positioning, form tracks for intracellular trafficking and, via rapid polymerisation at the barbed end, generate forces for dynamic processes such as cell migration, endocytosis and cell division. Together with the actin-associated motor protein myosin, actin generates specialised contractile structures such as the actomyosin ring during cytokinesis and the sarcomere of myofibres (Schwayer et al. 2016). Functional specialisation of F-actin is generated by the differential use of actin isoforms (Perrin \& Ervasti 2010). Within vertebrates, six actin genes exist, four of which are specific to muscle cells $\left(\alpha_{\text {cardiac, }}, \alpha_{\text {skeletal }}, \alpha_{\text {smooth }}\right.$ and $\left.\gamma_{\text {smooth }}\right)$, whereas two actins, $\beta_{\text {cyto }}$ - and $\gamma_{\text {cyto }}$-actin, are ubiquitous. Cytoplasmic F-actin can be composed of either or both $\beta_{\text {cyto }}$ - and $\gamma_{\text {cyto }}$-actin and the ratios of the two actin isoforms can affect polymer characteristics. A large arsenal of interacting proteins and post-translational modifications modulate the dynamics and properties of F-actin (Terman \& Kashina 2013, Pollard 2016). For example, F-actin-capping proteins can inhibit polymerisation, cross-linking proteins allow organisation of F-actin into higher order structures and severing proteins modulate filament number and dynamics (Pollard 2016). are integral components of the actomyosin contractile ring during cytokinesis (for reviews on these aspects; see Wittmann et al. 2001, Fung et al. 2014, Schwayer et al. 2016).

During these phases, a number of unique cytoskeletal features are also seen. The spermatogonial cytoskeleton, for example, is integral for the initial establishment of spermatogenesis. After birth, germ cells migrate to the basement membrane of the seminiferous tubules, where SSCs form a specialised niche between Sertoli cells (Fig. 1). The migration of germ cells into, and the maintenance of cell-cell interactions within, the niche relies on integrin and actin-based adhesion junctions (Kanatsu-Shinohara et al. 2008) and key actin regulators (Carlomagno et al. 2010, Xu et al. 2015). Reports that gonocytes and SSCs exhibit a polarized enrichment of $\alpha$-tubulin and acetylated $\alpha$-tubulin towards the basement membrane (Steger \& Wrobel 1994, Luo et al. 2010) also suggests microtubules aid in orienting and maintaining cells within the niche, particularly as tubulin acetylation correlates with decreased cell motility (Hubbert et al. 2002).

In both rodents and more simple non-mammalian systems, spermatogonia have been reported to undergo 'oriented cell division' in that the mitotic spindle angle is typically positioned perpendicular to the basement membrane (Morrison \& Kimble 2006, Lagos-Cabré \& Moreno 2008). This type of mechanism is often employed to control cell distribution, and in this instance likely allows one daughter cell to remain attached to the basement membrane, self-renewing the SSC progenitor, while sending the more apical 


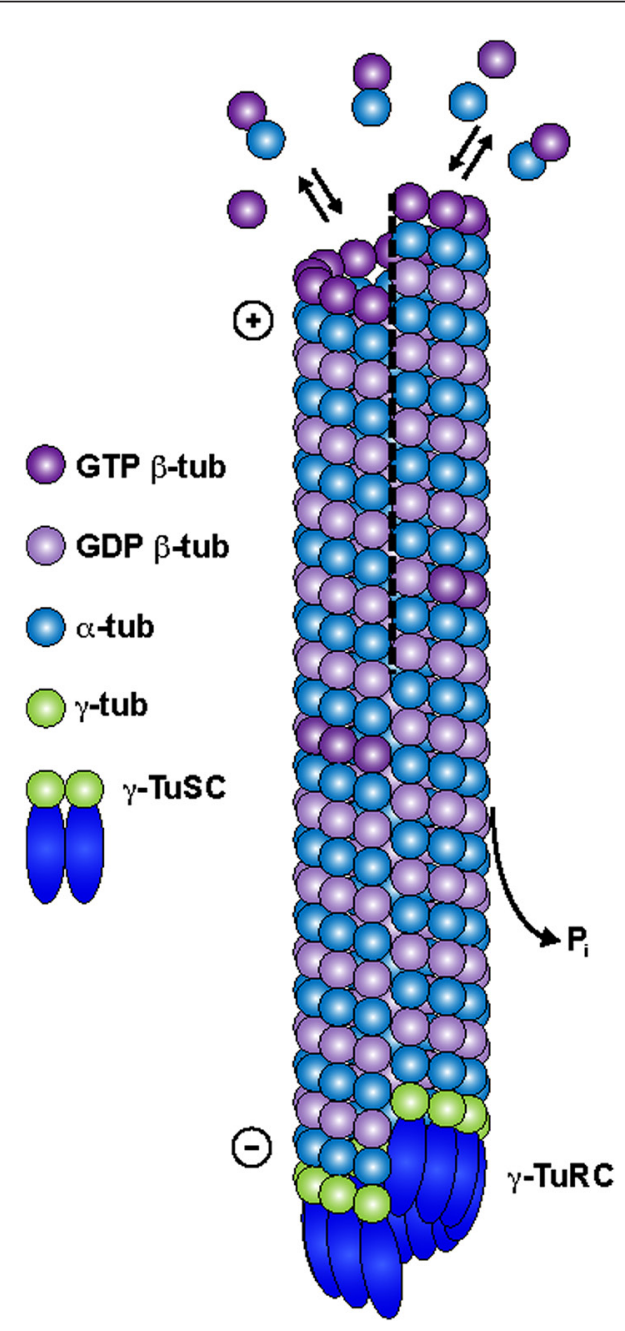

Box 2 Microtubule schematic.

\section{Microtubules}

Microtubules are hollow tubes of $\sim 25 \mathrm{~nm}$ in diameter, formed by GTP-mediated polymerisation of $\alpha$ - $\beta$-tubulin heterodimers. These $\alpha \beta$ tubulin dimers assemble, head-totail, into linear protofilaments, which associate laterally to form the microtubule circumference (Akhmanova \& Steinmetz 2015). In vivo, microtubule nucleation is reliant on $\gamma$-tubulin, which, in conjunction with $\gamma$-tubulin complex proteins, creates a template for microtubule nucleation (Oakley et al. 2015). Like actin, microtubules are intrinsically polarised; they have a plus-end (exposing $\beta$-tubulin) and a minus-end (exposing $\alpha$-tubulin) (Akhmanova \& Steinmetz 2015). The minus-end is inherently stable and, in vivo, is frequently anchored to a microtubule-organising centre. Conversely, the plus-end exhibits 'dynamic instability', spontaneously switches between states of rapid depolymerisation (catastrophe) and polymerisation (rescue). This instability is powered by GTP hydrolysis; GTP-bound $\beta$-tubulin stabilises the plusend, whereas GDP-bound $\beta$-tubulin destabilises the lattice and, if exposed at the plus-end, initiates catastrophe. Dynamic instability allows for the rapid remodelling of microtubule networks and for the generation of pushing and pulling forces using polymerisation and depolymerisation respectively. Within most cell types, microtubules exist as large polarised arrays that extend throughout the cytoplasm, providing infrastructure for organelle positioning and movement, trafficking of proteins and vesicles and establishing and maintaining cell shape and polarity. Microtubules also form the structural basis of centrioles, the mitotic and meiotic spindles and cilia. To function effectively, microtubules rely on a diversity of microtubule-associated proteins (MAPs), including motor proteins, cross-linking MAPs, severing enzymes, nucleators and regulators of dynamic instability (Subramanian \& Kapoor 2012). Moreover, posttranslational tubulin modifications and the use of different $\alpha$ - and $\beta$-tubulin isoforms and paralogues $(\delta, \varepsilon, \zeta, \eta, \theta$, $1, \kappa)$ generate a complex 'tubulin code' (Dutcher 2001, Janke 2014), which appears to specify the MAP binding and activity required at specific sites. daughter into the differentiating pathway. Positioning of the spindle in this way is dependent on the interplay between astral spindle microtubules, the microtubuleassociated motor protein, dynein and the cell cortex (Lagos-Cabré \& Moreno 2008, Mora-Bermúdez et al. 2014, Tame et al. 2014).

With the exception of the initial SSC self-renewing divisions, dividing germ cells exhibit incomplete cytokinesis, with cells maintaining stable cytoplasmic intercellular bridges. By allowing gene product sharing between related cells, such bridges likely facilitate the synchrony of spermatogenesis, in addition to allowing haploid germ cells to remain phenotypically diploid (Haglund et al. 2011). The initial formation of these bridges follows the typical events of early cytokinesis wherein an actomyosin contractile ring promotes ingression of the cleavage furrow and compacts equatorial spindle microtubules into a dense midbody. However, instead of undergoing abscission, the midbody is converted into a stable electron-dense bridge. Although microtubules are quickly lost from the developing bridges (Greenbaum et al. 2007), actin, $\delta$-tubulin, keratin- 5 and multiple cytoskeletal-interacting proteins have been identified as components (Haglund 


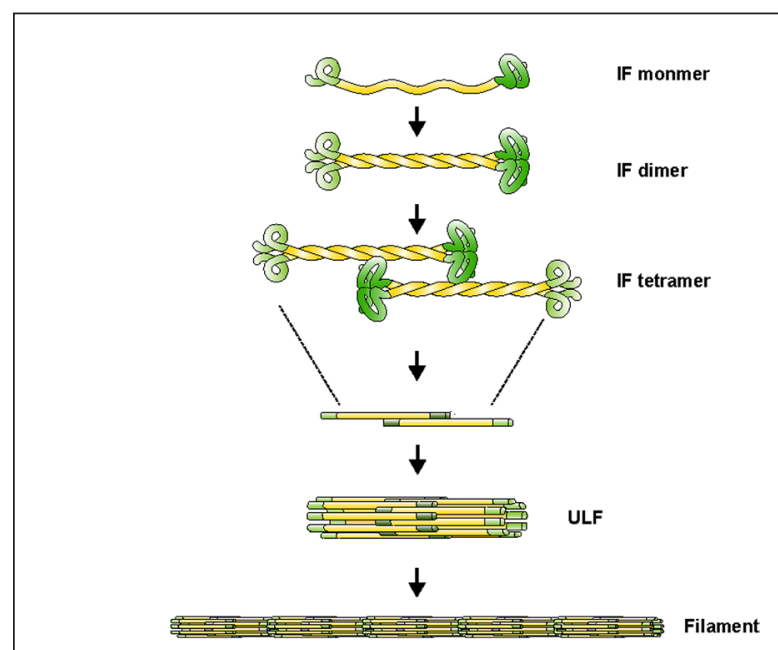

Box 3 IF schematic.

\section{Intermediate filaments}

Intermediate filaments (IF) are a superfamily of six classes of non-polar, $10 \mathrm{~nm}$ diameter fibres encoded by over 70 different genes (Szeverenyi et al. 2008, Köster et al. 2015). IFs are predominantly cytoskeletal with the exception of type V IF proteins (lamin A, B and C), which form the nucleoskeleton (Szeverenyi et al. 2008). Although genetically diverse, the basic structure of IFs is largely consistent across the six subfamilies. Unlike the globular actin and tubulin proteins, monomeric IF proteins are fibrous with a central elongated $\alpha$-helical coil, flanked by non-helical 'head' and 'tail' ends. Dimerisation is not dependent upon nucleotides. Rather, parallel monomers inter-coil their central domains, and typically an IF precursor pool of non-polar tetramers forms by the antiparallel, lateral half-staggering of two of these coiledcoil dimers. IFs assemble from this pool in a stepwise manner via the lateral association of eight tetramers into unit-length filaments (ULFs), followed by the longitudinal annealing of multiple ULFs. Due to this laterally layered arrangement, the basic IF structure is extremely flexible, providing tensile strength to cytoskeletal structures. Lateral displacement of tetramers and dimers relative to one another via 'subunit gliding', in addition to straightening of the $\alpha$-helix coils, allows filaments to be elongated by up to $240 \%$ of their normal length (Köster et al. 2015). Organisation of IFs into complex structures, such as bundles, fibres or mesh-like networks, depends upon IF type, acquisition of post-translational modifications and interactions with binding proteins (bundling and crosslinking proteins, chaperones, kinases, apoptosis-related proteins and nuclear proteins; Köster et al. 2015). et al. 2011), and actin is essential for their continued integrity (Russell et al. 1987). In addition, septins 2, 7 and 9 localise to intercellular bridges during their initial formation (Greenbaum et al. 2007).

Although male meiosis shares many basic cytoskeletal aspects with mitosis, there are a number of key differences. During the first meiotic prophase, for example, homologous chromosomes pair and exchange genetic material via recombination, to ensure genetic diversity of the gamete. In preparation for pairing, rapid movements converge chromosomes, via their telomeres, at one nuclear pole. Cytoplasmic microtubules drive these movements (Morimoto et al. 2012), interacting with telomeres via KASH5-SUN1-based LINC (linker of nucleoskeleton and cytoskeleton) complexes spanning the nuclear membrane (Morimoto et al. 2012, Horn et al. 2013). The meiotic prophase-specific IF, lamin C2, which is enriched in the nuclear lamina at telomere-LINC attachment sites, is also critical for this process (Table 1; Alsheimer et al. 1999, Jahn et al. 2010). Indeed, due to its increased mobility compared to other lamins (Jahn et al. 2010), lamin C2 likely allows for greater transmission of microtubule-derived forces across the nuclear envelope. Once converged, chromosome pairing and recombination is facilitated by the formation of specialised protein-based structures termed synaptonemal complexes. The formation of these complexes may rely on actin dynamics, as removal of ALKBH4, a protein that influences the ability of nonmuscle myosin II to interact with F-actin, prevents the formation of synaptonemal complexes in spermatocytes leading to apoptosis of these cells (Nilsen et al. 2014).

Within the subsequent phases of meiosis, notable peculiarities in spindle microtubule nucleation and size have been reported in Drosophila, and preliminary evidence suggests similar peculiarities exist in mammalian spermatogenesis. Unlike female meiotic germ cells, which in most species are acentriolar, spermatocytes predominantly nucleate microtubules from centrioles (Kallio et al. 1998, Giansanti et al. 2008, Riparbelli \& Callaini 2011) and, while confirmation is needed in mammals, research in non-mammalian 


\begin{tabular}{|ll} 
Septins \\
Septins are a family of GTP-binding proteins capable of \\
polymerising into non-polar filaments that in turn can be \\
organised into bundles, rings and mesh-like structures \\
(Mostowy \& Cossart 2012, Fung et al. 2014, Valadares \\
et al. 2017). Within mammals, 13 septin proteins have \\
been identified (septin 1-12 and 14) and classified into \\
four subgroups SEPT2 (septin 1, 2, 4, 5), SET3 (septin 3, \\
9, 12), SEPT6 (septin 6, 8, 10, 11, 14) and SEPT7 (septin \\
7). Typically, septins self-assemble into either hexameric \\
or octameric hetero-oligomers with three or four septin \\
subtypes contributing. Within these oligomers, monomers \\
are arranged symmetrically, interacting via alternate G \\
and NC interfaces. A mixture of octamers and hexamers \\
then assemble end-to-end to form filaments. Septin \\
filament composition is thus diverse and cell and function \\
specific, with a number of septin genes showing tissue- \\
specific expression (Mostowy \& Cossart 2012). Although \\
the precise mechanisms governing septin assembly, \\
disassembly and architecture are unresolved, interactions \\
with microtubules, F-actin and phospholipid membranes \\
all appear to influence the higher order organisation \\
of septins. Likewise, while septin function is poorly \\
understood relative to other cytoskeletal elements, key \\
roles have been identified in cytokinesis, the formation of \\
diffusion barriers, microtubule dynamics and the release \\
of neurotransmitters (Fung et al. 2014, Valadares et al. \\
2017).
\end{tabular}

systems suggests this pathway is essential for effective male meiotic spindle formation (Giansanti et al. 2008, Riparbelli \& Callaini 2011). This also differs from typical spindle formation in somatic cells and spermatogonia, wherein nucleation can occur at centrioles but is not dependent on it (Basto et al. 2006, Giansanti et al. 2008, Riparbelli \& Callaini 2011). Interestingly, a large difference in spindle size between mitosis and meiosis has been reported in Drosophila, with meiotic spindles consistently the larger of the two (Cenci et al. 1994). This reliance on centriole-based nucleation thus potentially accommodates the unusually large amount of tubulin required for male meiosis. The functional significance of these different spindle sizes is unclear; however, a correlation between meiotic spindle size and subsequent sperm flagellum size in Drosophila has prompted speculation that tubulins used in meiosis are stored and reutilized for flagellum formation (Lattao et al. 2012). However, it is possible that spindle and flagellum formation are simply driven by the same nucleating pathway, and similarities in nucleation efficiency and tubulin quantity arise as a consequence. Indeed, centrosome-nucleating activity and spindle size are also believed to be correlated (Lattao et al. 2012).

\section{Spermiogenesis}

Following the end of meiosis, haploid round spermatids enter spermiogenesis as small, unpolarised cells with an unremarkable cytoskeletal network. As they undergo progressive remodelling, however, this network is reorganised into multiple complex, and in some cases, unique, cytoskeletal structures that are integral to spermatid remodelling and sperm function.

\section{Acrosome biogenesis}

One of the earliest events in spermiogenesis is the formation of the acrosome, an apical nuclear cap, rich in enzymes required for sperm penetration of the oocyte cumulus complex. Acrosome biogenesis begins with trafficking of proacrosomal vesicles to the nucleus from both the trans-Golgi stacks and from an endocytic pathway (Fig. 2; Elkis et al. 2015). These vesicles coalesce, adhere to, and progressively spread over, the nuclear envelope. As evidenced by studies wherein various cytoskeletal proteins are disrupted, acrosome biogenesis and integrity is reliant on an intact and diverse cytoskeletal network (Vogl 1990, Moreno 


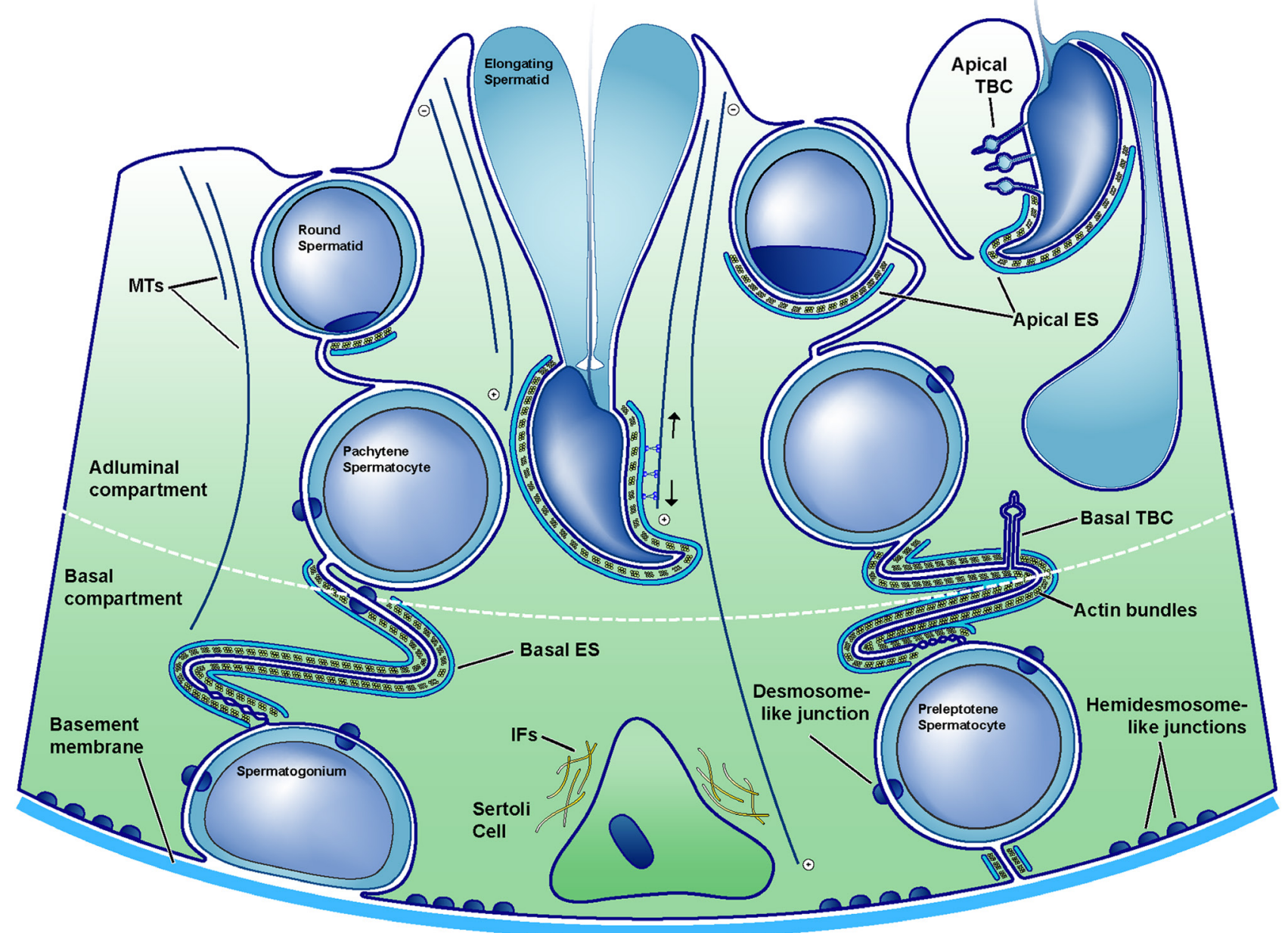

Figure 1 Cytoskeletal organisation of the seminiferous epithelium. Sertoli cells possess a dynamic cytoskeletal network consisting predominantly of actin filaments, IFs and microtubules (Vogl et al. 2008). Actin-based adhesion junctions (ectoplasmic specialisations (ESs) interspersed with adherens, gap and tight junctions) are integral in facilitating adhesion and communication between adjacent Sertoli cells (Vogl et al. 2014, Stanton 2016), and in physiologically segregating the seminiferous tubules into basal and apical compartments and thus are referred to as the 'blood-testis barrier' (Mital et al. 2011, Kaur et al. 2014). Dynamic remodelling of this junctional complex by actin-based endocytic tubulobulbar complexes (TBCs) likely allows spermatocytes to move from the basal to the apical compartment (Vogl et al. 2014). Sertoli cells also form ES and adherens junctions with spermatocytes and spermatids to allow Sertoli cells to adhere and transmit forces to developing germ cells (Romrell \& Ross 1979, Kierszenbaum et al. 2007), in addition to forming TBCs with spermatids during spermiation (O'Donnell et al. 2011, Vogl et al. 2014). IFs are present throughout the Sertoli cytoplasm, and in particular, are concentrated around the Sertoli cell nucleus (Amlani \& Vogl 1988, Vogl et al. 2008). IFs also contribute to specialised intercellular junctions (desmosomes) and junctions with the basement membrane (hemi-desmosomes; Vogl et al. 2008). Microtubules are predominately located in the apical processes of Sertoli cells that surround developing spermatids (Vogl et al. 2008), and together with microtubule-based motor proteins (Miller et al. 1999, Guttman et al. 2000, Vaid et al. 2007), are thought to provide tracks for the translocation of spermatids within the depth of the seminiferous epithelium via interactions with the apical ESs.

et al. 2006, Shen et al. 2014). Eukaryotic vesicle trafficking is typically mediated by microtubule-based mechanisms for long-range movement followed by actin-based trafficking for more precise local delivery, and several lines of evidence suggest proacrosomal vesicle trafficking adheres to such a model.

Immunolocalisation studies have shown proacrosomal vesicles are decorated with the microtubule-based kinesin-14 motor KIFC1, in addition to the F-actinbased motor myosin-Va and its receptor RAB 27A/B (Yang \& Sperry 2003, Kierszenbaum et al. 2004).
Consistent with this, reduced KIFC1 expression has been associated with defective acrosome formation in both humans and mice (Zhi et al. 2016). Similarly, treatment of spermatids with the microtubule-depolymerising agent nocodazole specifically disrupts the initial steps of acrosome formation (Moreno et al. 2006). Multiple microtubule-interacting proteins have also been implicated in proacrosomal vesicle transport, including endocytic sorting regulators USP8/UBPy and HOOK1 (Moreno et al. 2006, Berruti et al. 2010, MaldonadoBáez et al. 2013, Berruti \& Paiardi 2015) and GMAP210 
Table 1 Mouse models relevant to the function of intermediate and septin filaments in spermatogenesis.

\begin{tabular}{|c|c|c|c|c|c|c|}
\hline Cytoskeletal type & Gene & Protein & Testis localisation & Spermatogenesis phenotype & $\begin{array}{l}\text { Function in } \\
\text { somatic cells }\end{array}$ & References \\
\hline \multirow[t]{3}{*}{$\begin{array}{l}\text { Intermediate } \\
\text { filaments }\end{array}$} & Lmna & Lamin A and C & Spermatid acroplaxome & $\begin{array}{l}\text { siRNA knockdown of Lmna, } \\
\text { causing loss of lamin A/C } \\
\text { proteins in mice, disrupts } \\
\text { acrosome vesicle docking, } \\
\text { maintenance of acrosome } \\
\text { integrity, and results in } \\
\text { abnormal spermatid } \\
\text { nuclear morphology }\end{array}$ & $\begin{array}{l}\text { Key component of the } \\
\text { nuclear lamina }\end{array}$ & $\begin{array}{l}\text { Shen et al. } \\
(2014)\end{array}$ \\
\hline & & Lamin C2 & $\begin{array}{l}\text { Telomere-nuclear } \\
\text { envelope attachment } \\
\text { sites in spermatocytes } \\
\text { during meiotic } \\
\text { prophase I }\end{array}$ & $\begin{array}{l}\text { Lamin } C 2^{-/-} \text {mice (targeted } \\
\text { deletion of the lamin C2 } \\
\text { isoform of the Lmna gene) } \\
\text { exhibit defective meiotic } \\
\text { synapsis, resulting in } \\
\text { complete meiotic failure } \\
\text { and an absence of } \\
\text { postmeiotic male germ cells }\end{array}$ & $\begin{array}{l}\text { Lamin C2 is germline } \\
\text { specific, however its } \\
\text { ectopic expression in } \\
\text { somatic cells results } \\
\text { in nuclear } \\
\text { deformation and } \\
\text { alters distribution of } \\
\text { nuclear envelope } \\
\text { proteins }\end{array}$ & $\begin{array}{l}\text { Jahn et al. } \\
\text { (2010), Link } \\
\text { et al. (2013) }\end{array}$ \\
\hline & Vim & Vimentin & $\begin{array}{l}\text { Present throughout the } \\
\text { Sertoli cell cytoplasm }\end{array}$ & $\begin{array}{l}\mathrm{Vim}^{-/-} \text {mice have no obvious } \\
\text { spermatogenic defects }\end{array}$ & $\begin{array}{l}\text { Anchors organelles in } \\
\text { the cytoplasm and } \\
\text { maintains cell shape }\end{array}$ & $\begin{array}{l}\text { Vogl et al. } \\
\text { (1996) }\end{array}$ \\
\hline \multirow[t]{2}{*}{ Septin filaments } & Sept4 & Septin-4 & $\begin{array}{l}\text { Annulus of spermatids } \\
\text { and spermatozoa }\end{array}$ & $\begin{array}{l}\text { Spermatozoa of Sept4 }{ }^{-/-} \\
\text {mice lack the annulus (and } \\
\text { as such substances diffuse } \\
\text { between the mid-piece and } \\
\text { the rest of the sperm } \\
\text { flagella), have } \\
\text { mitochondrial } \\
\text { abnormalities, retention of } \\
\text { the cytoplasmic droplet, are } \\
\text { immotile and fail to } \\
\text { capacitate. Sept } 4^{-/-} \text {mouse } \\
\text { testes also have reductions } \\
\text { in Septins } 1,2,6,7 \text { and } 11, \\
\beta \text {-actin and cytochrome } \\
\text { protein levels }\end{array}$ & $\begin{array}{l}\text { Possible roles in } \\
\text { exocytosis, } \\
\text { cytokinesis and } \\
\text { neuronal } \\
\text { differentiation and } \\
\text { growth }\end{array}$ & $\begin{array}{l}\text { Ihara et al. } \\
\text { (2005), Kissel } \\
\text { et al. (2005) }\end{array}$ \\
\hline & Sept12 & Septin-12 & $\begin{array}{l}\text { HTCA, mid-piece and } \\
\text { annulus of spermatids } \\
\text { and spermatozoa, and } \\
\text { manchette of sperma- } \\
\text { tids }\end{array}$ & $\begin{array}{l}\text { Spermatids and spermatozoa } \\
\text { of Sept } 12^{+/} \text {mice exhibit } \\
\text { abnormal nuclear morphol- } \\
\text { ogy and lack of or defective } \\
\text { flagella }\end{array}$ & Not investigated & $\begin{array}{l}\text { Lin et al. } \\
\text { (2011), Kuo } \\
\text { et al. (2013), } \\
\text { Yeh et al. } \\
(2015)\end{array}$ \\
\hline
\end{tabular}

and IFT88 for Golgi-derived vesicles (Kierszenbaum et al. 2011). Recent research has also revealed that microtubules facilitate the correct spatial orientation of the Golgi stacks during acrosome biogenesis (Elkis et al. 2015). Specifically, interactions between microtubules and the Golgi-associated protein, TMF/ ARA160, are responsible for the unique rotation of the Golgi, so that the trans-Golgi stacks face the spermatid nucleus. However, whether correct Golgi orientation is absolutely required for proacrosomal vesicle delivery requires further clarification. Indeed, there is some contention as to whether microtubules are actually required for delivery of proacrosomal vesicles from the Golgi. Recent data suggest that nocodazole treatment only disrupts the delivery of plasma membrane, not Golgi, derived acrosomal components (Berruti \& Paiardi 2015); however, the transport of only one Golgi-derived acrosomal protein was assessed. Given the close proximity of the Golgi to the acrosome, it is possible actin-based mechanisms are more important for this pathway. Microtubules have also been proposed to facilitate the final shaping of the acrosome in lower order species. Of interest, studies in crustaceans have revealed a novel microtubule-based structure called that acroframosome. It is an 'umbrella-like' scaffold around the acrosome in mid to late spermiogenesis, and the structure is consistent with a possible role in either driving formation or structurally reinforcing the characteristic apical acrosomal spike of crustacean sperm ( $\mathrm{Li}$ et al. 2010). While there has been speculation that a similar structure may exist in mammals (Wei \& Yang 2018), this is far from certain and should be explored more closely. Within early round mammalian spermatids, microtubules are present as a randomly arranged, dense cortical array and, in direct contrast to crustaceans, as spermiogenesis proceeds microtubules almost entirely polarise to the caudal half of the spermatid nucleus.

Acrosome biogenesis is further facilitated by the acroplaxome, a dense F-actin/keratin-5 cytoskeletal plate in the subacrosomal space (Kierszenbaum et al. 


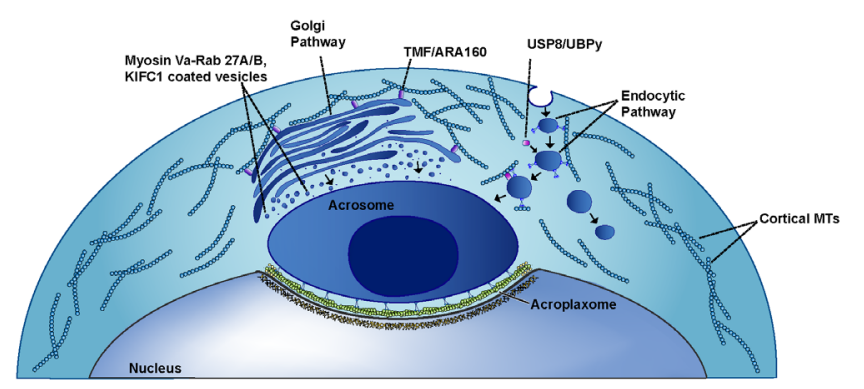

Figure 2 Cytoskeletal aspects of acrosome biogenesis. Vesicles derived from the trans-Golgi stacks and from endocytic pathways drive the formation of the acrosome. During this process, a dense cortical microtubule array is observed in the spermatid cytoplasm, and proacrosomal vesicles are thought to be transported along these microtubules to the site of acrosome biogenesis. Endocytic vesicles are directed to the acrosome by USP8/UBPy, which can bind both the vesicles and microtubules (Berruti et al. 2010, Berruti \& Paiardi 2015). Golgi-derived proacrosomal vesicles are coated with actin-based motor protein myosin-Va and its receptor Rab 27A/B, in addition to the microtubule-based motor protein, KIFC1, suggesting transport to the acrosome occurs via both microtubule and actinbased mechanisms (Yang \& Sperry 2003, Kierszenbaum et al. 2004). However, the reliance of Golgi-derived vesicles on microtubuledependent transport is debated (Berruti \& Paiardi 2015). TMF/ ARA160-dependent interactions between microtubules and the Golgi, ensure that the trans-Golgi stacks face the acrosome (Elkis et al. 2015). MT, microtubule.

2003b; Fig. 3). The acroplaxome appears to adhere to the developing acrosomal sac to the nuclear envelope and facilitates its transverse spreading. Consistent with this, cytochalasin D disruption of F-actin results in nuclear-acrosome detachment and disruption to the expanding edge of the acrosome (Vogl 1990). The presence of myosin-Va between the developing acrosomal sac and the acroplaxome F-actin tract has prompted the hypothesis that it may facilitate acrosome spreading (Kierszenbaum et al. 2004; Fig. 3E); however, this requires further investigation. The acroplaxome appears to be anchored to the nuclear envelope by interactions between keratin within the acroplaxome and the IF-based network in the nuclear envelope. Notably, knockdown of lamin A/C-based nuclear IFs disrupts acrosome vesicle docking and the maintenance of acrosome integrity (Table 1; Shen et al. 2014). Moreover, electron microscopy has revealed that the caudal marginal ring of the acroplaxome is defined by a desmosome-like structure, consisting of keratin-5based IFs, which connects the descending edge of the acrosome to the nuclear lamina (Kierszenbaum et al. 2003b; Fig. 3B and E).

\section{Flagella formation}

The sperm flagellum, formed during spermiogenesis, is a modified motile cilium. It possesses a typical basal body-derived 9+2 central microtubule core, the axoneme, ensheathed along most of its length by sperm-specific accessory structures (including keratin-like outer dense fibres (ODF), a mitochondrial sheath and a fibrous sheath; Fig. 4). Microtubule dynamics are thus well established to underpin the structure and function of the flagella. More recently, however, the importance of F-actin and septins has been highlighted.

Axonemeformation is initiated early in spermiogenesis, with the polarisation of the centrosome to the caudal pole of the cell. As is typical of ciliogenesis, the spermatid centrosome matures into a basal body that is capable of docking onto the plasma membrane and extending an axoneme. However, unlike typical ciliogenesis, the basal body also docks the nuclear membrane, driving formation of the head-to-tail coupling apparatus (HTCA) (Figs 3 and 4). The distal (or mother) centriole of the basal body, which docks to the plasma membrane, orients along the longitudinal axis of the eventual flagellum and axonemal microtubules nucleate from this template (Fawcett \& Phillips 1969).

While the mechanisms driving these events have been given minimal attention in spermatids, insights from somatic cells indicate actin- and microtubule-related processes are integral for these initial phases. Somatic basal body maturation requires several modifications to the microtubule scaffold of the distal centriole, including the acquisition the distal appendages (Sillibourne et al. 2013, Tanos et al. 2013, Ye et al. 2014), the removal of a CP110-CEP97 distal centriole cap, which inhibits axoneme microtubule extension (Spektor et al. 2007), followed by the acquisition of the pre-ciliary vesicle, which ultimately forms the ciliary membrane (Sorokin 1962). Of note, the delivery of the pre-ciliary vesicle to the basal body requires dynein-based transportation along microtubules, followed by myosin-Va-dependent transportation along ARP2/3-associated F-actin networks (Wu et al. 2018). Similarly, plasma membrane docking typically requires interactions with cortical F-actin networks to drive docking and correct orientation at the plasma membrane (Dawe et al. 2007, Park et al. 2008, Werner et al. 2011) and focal adhesion proteins, such as FAK, vinculin and paxillin, appear to facilitate these actin-microtubule interactions (Antoniades et al. 2014). However, whether this mechanism is conserved in spermatids, particularly in the spermatid-specific process of nuclear envelope-basal body docking requires investigation. Indeed, different mechanisms likely drive basal body-nuclear attachment, with inner nuclear membrane protein SUN5, being essential for the ongoing integrity, although not the initial formation, of the HTCA-nuclear envelope attachment (Fig. 4A; Shang et al. 2017). Other proteins such as septin-12 (see below), PMFB1 and ODF1 have also been implicated in HTCAnuclear envelope attachment (Kefei et al. 2014, Yeh et al. 2015, Zhu et al. 2018). The initial polarisation of the centrosome is also unexplored in spermatids, although 


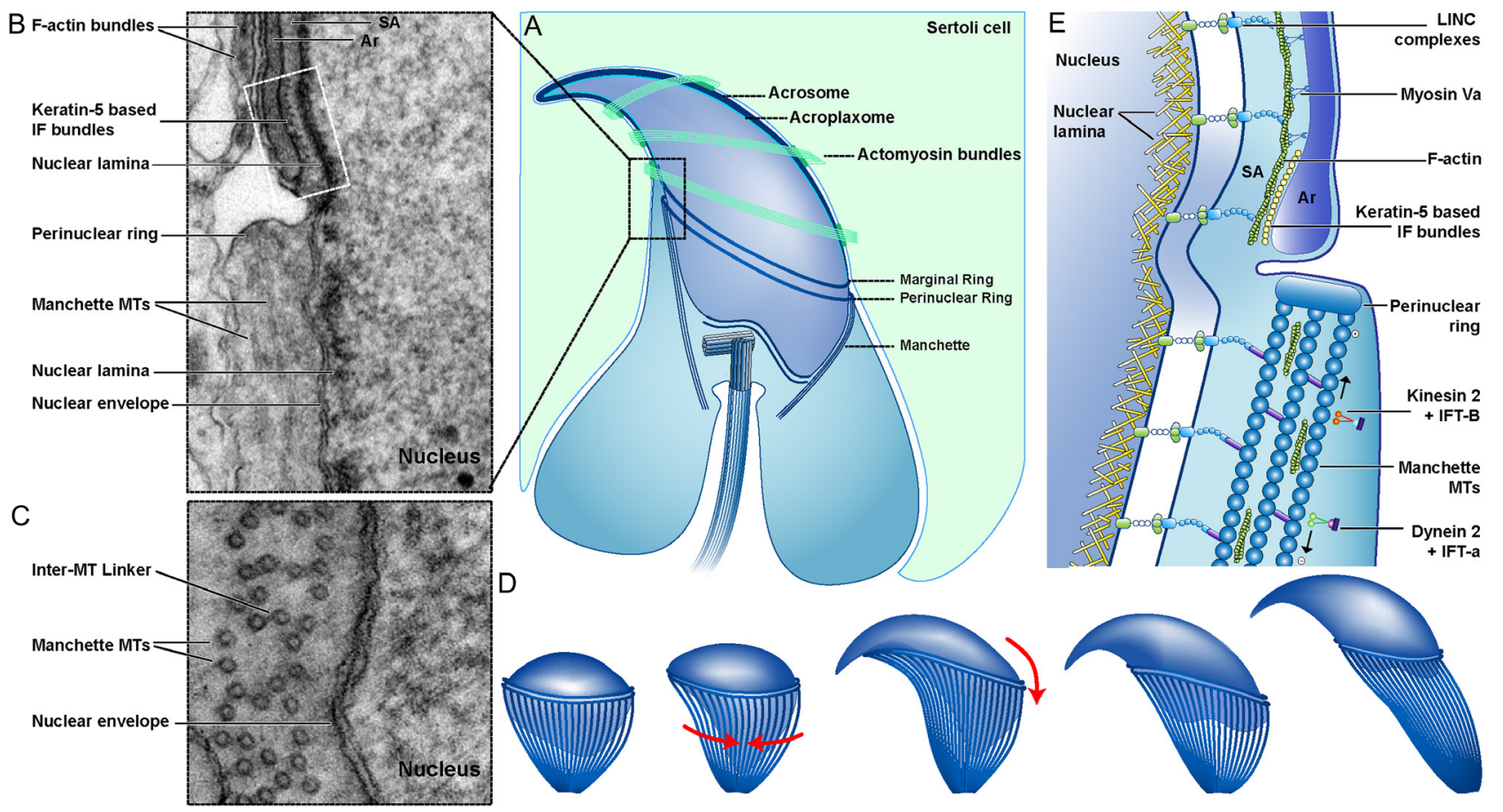

Figure 3 Cytoskeletal structures in spermatid head shaping. Nuclear remodelling in spermatids is thought to be driven by three key elements: (1) the acroplaxome, an actin-keratin-based cytoskeletal plate, (2) extracellular forces from the actomyosin bundles residing in the surrounding Sertoli cell and (3) the manchette, a transient microtubule-based 'skirt' (Kierszenbaum et al. 2007, Lehti \& Sironen 2016). The overall relationship of these three structures, in the context of a mouse elongating spermatid, is illustrated in (A). The structure of the sperm head shaping machinery can be seen in an electron micrograph (B) and a schematic (E) of a mouse spermatid. The transverse aspect of the manchette is also shown via in an electron micrograph in (C). (D) During spermiogenesis the manchette progressively moves down the spermatid head, while concomitantly constricting to sculpt the base of the nucleus (Russell et al. 1991, Lehti \& Sironen 2016). This is accompanied by expansion of the acrosome and underlying acroplaxome (Kierszenbaum et al. 2004, 2007). Ar, acrosome; ES, ectoplasmic specialisation; IF, intermediate filament; MT, microtubule; SA, subacrosomal space.

similar events in somatic cells utilise dynein and the actin motor, non-muscle myosin II (Liu et al. 2013).

While many of the aforementioned aspects of somatic centriole and ciliogenesis dynamics are likely conserved in spermatids, it should be noted that evidence indicates that there are at least some spermatidspecific mechanisms. Mouse spermatids lacking the microtubule regulating protein, KATNAL2, exhibit a failure of basal body-plasma membrane docking and axoneme extension; however, aside from spermatogenic defects, the mice are overtly healthy, suggesting somatic ciliogenesis is not catastrophically affected (Dunleavy et al. 2017). In addition, after ciliogenesis commences, the spermatid basal body undergoes additional unique remodelling steps. The minus ends of the distal centriole microtubules splay outwards, and specific centriolar proteins become enriched in rod-like formations while other centriole proteins are reduced, resulting in an almost unrecognisable 'atypical' centriole (Fishman et al. 2018). The functional significance of these unique changes, however, remains to be elucidated.

A role for septins in flagella formation is also emerging. Typical somatic cilia are physiologically segregated into a cytoplasmic centriole segment and an axonemal segment via a specialised transition zone. A septin-based diffusion barrier at the junction of this zone and the axonemal segment is integral to this compartmentalisation and thus cilia formation. Likewise in sperm, an analogous filamentous septin-based ring known as the annulus forms at the distal tip of the centriole just after centriole docking. In the terminal steps of spermatid maturation, this ring progressively migrates along the axoneme by an unknown mechanism, ultimately residing at the junction between the mid-piece and the principal piece (Fig. 4A; Kissel et al. 2005, Sugino et al. 2008, Lin et al. 2011). Evidence suggests the annulus establishes a diffusion barrier physiologically segregating the mid-piece from the principal and end pieces (Table 1; Kwitny et al. 2010), leading to the proposal that the annulus together with the mid-piece represents a modified transition zone. Septin-12 has also been localised to the HTCA of spermatozoa (Lin et al. 2011, 2012, Kuo et al. 2013) and appears to be important for its structural integrity, potentially linking cytoskeletal elements in the HTCA to SUN4 and the nuclear lamina (Fig. 4A and Table 1; Yeh et al. 2015). 


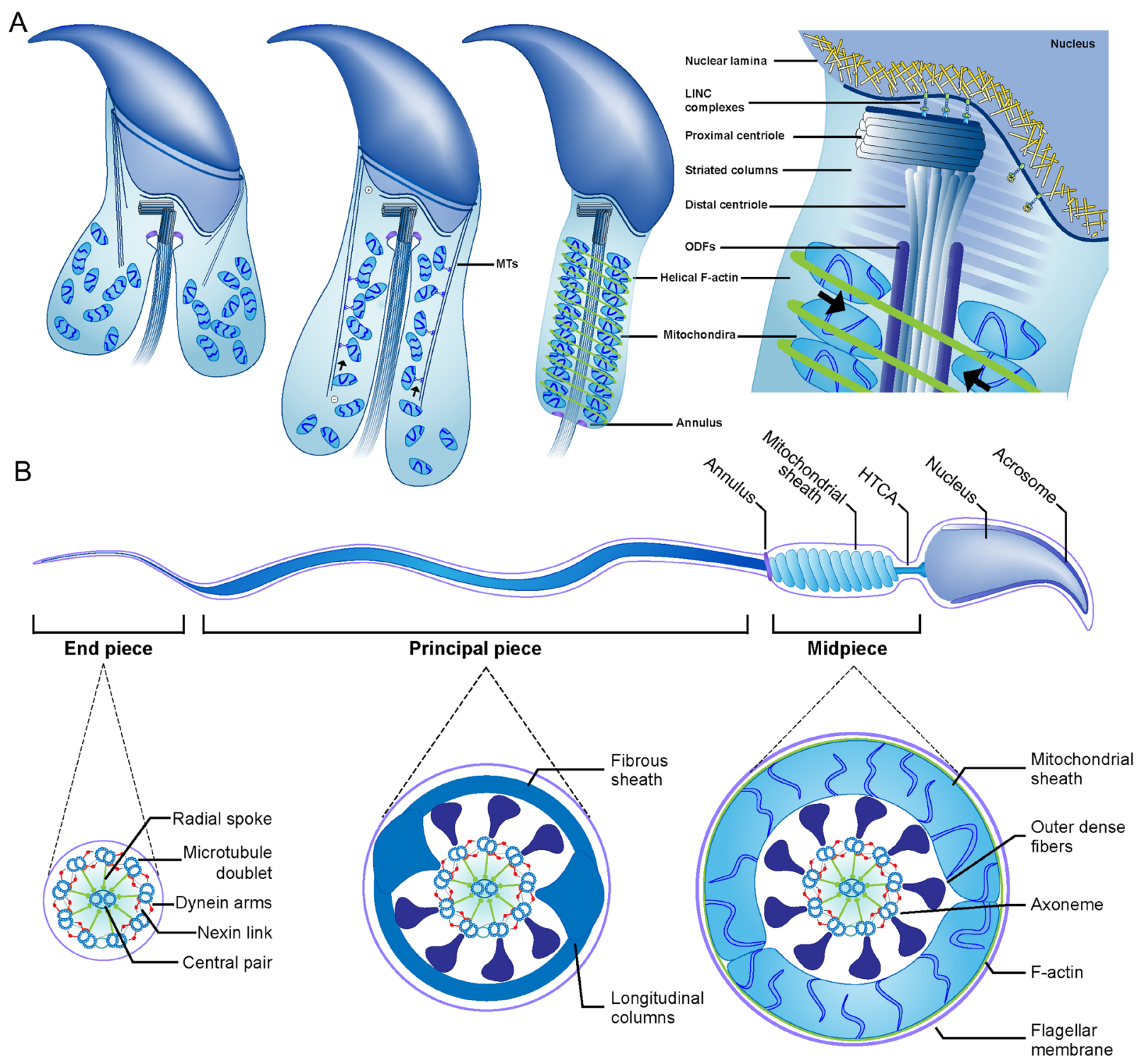

Figure 4 Cytoskeletal aspects of the sperm flagellum and its development. The proposed model of mitochondrial sheath and HTCA formation is illustrated in (A). As spermiogenesis proceeds, mitochondria are organised into longitudinal rows in the cytoplasmic lobes of the spermatids in preparation for loading onto the ODF. Given that mitochondria can interact with KLC3, it is possible this organisation is driven via kinesin-based transport up the microtubules of the manchette (Zhang et al. 2012). After caudal migration of the annulus, an F-actin helix is observed around the mitochondrial sheath, which may either drive compaction of mitochondria around the ODF or provide structural integrity to the mitochondrial sheath (Gervasi et al. 2018). The HTCA is composed of a proximal and distal centriole embedded within a specialised pericentriolar material known as the striated columns. The proximal centriole attaches to the nuclear envelope via the associated dense capitulum. The LINC complex protein, SUN5, connects the nuclear lamina to the capitulum via an unknown mechanism (Shang et al. 2017). Septin-12, which is present throughout the HTCA, is also essential for HTCA integrity, likely due to its interactions with SUN4-based LINC complexes in the nuclear membrane (Lin et al. 2011, 2012, Kuo et al. 2013, Yeh et al. 2015). (B) The flagella of mature spermatozoa is structurally characterised by three distinct regions: the midpiece, principal and end pieces. At the transverse aspect, the midpiece is characterised by an outer mitochondrial sheath encasing a ninefold array of ODF and a 9+2 motile axoneme (Fawcett 1975, Lindemann \& Lesich 2016). This region connects to the sperm head via the head-tail coupling apparatus (HTCA) (Fawcett \& Phillips 1969) and due to the presence of a septin-based diffusion barrier in the midpiece annulus, this region is believed to represent a modified transition zone (Kwitny et al. 2010). Within the principal piece, the mitochondrial sheath is absent; instead, a fibrous sheath encases the ODF and axoneme core (Fawcett 1975, Lindemann \& Lesich 2016). Moreover, longitudinal columns of fibrous sheath replace ODFs 3 and 8 . The ODF and fibrous sheath both terminate at the end of the flagella principal piece. As such, the end piece is the thinnest region of the sperm flagella, containing only the $9+2$ axoneme surrounded by a plasma membrane (Fawcett 1975, Lindemann \& Lesich 2016). Flagellar movement is dependent on the central axoneme. The dynein arms 'slide' adjacent microtubule doublets in relation to one another in an ATP-dependent process (Satir 1968, Summers \& Gibbons 1971, Gibbons \& Gibbons 1973). Due to both nexin linkers and the attachment of microtubule doublets to the basal body restricting sliding, the action instead results in axoneme bending. 
Once axoneme extension initiates in round spermatids, the delivery of constituents required for axoneme and, possibly, fibrous sheath assembly is likely achieved via a modified intraflagellar transport (IFT) pathway (O'Donnell \& O'Bryan 2014, Lehti \& Sironen 2016). IFT is an evolutionarily conserved mechanism, wherein motor proteins transport large protein complexes along the axoneme microtubules (Rosenbaum \& Witman 2002). Axoneme growth occurs exclusively by tubulin addition at the distal tip (Johnson \& Rosenbaum 1992); however, protein synthesis is restricted to the cell cytoplasm. IFT thus provides an essential delivery mechanism. Cargoes are transported by IFT-A and IFT-B complexes in association with kinesin-2 and dynein-2 family motor proteins (Rosenbaum \& Witman 2002, Taschner \& Lorentzen 2016), and notably, various IFT-A and -B complex proteins and the kinesin II protein, KIF3A, are essential for spermatid axoneme formation. Ift20, Ift25, Ift27, Ift88, Ift140 and Kif3A mutant mice all exhibit either short, deformed or absent flagella, with disorganised or absent axoneme components and associated ODF and fibrous sheath defects (Kierszenbaum et al. 2011, Lehti \& Sironen 2016, Zhang et al. 2016, Liu et al. 2017, Zhang et al. 2017a,b). Likewise, a RABL2-dependent IFT pathway has been implicated in the delivery of key components to the fibrous sheath (Lo et al. 2012).

While IFT is involved in building the axoneme earlier in spermiogenesis, intramanchette transport (IMT) (Fig. 3E) is likely involved in the final steps of sperm flagellum and accessory structure assembly after spermatid elongation commences. The manchette is a transient microtubulebased sheath present around the spermatid nucleus during the latter half of spermiogenesis (see Nuclear remodelling' section). Flagella components, and notably ODF proteins, are transported along manchette microtubules, as are vesicles, IFT complex proteins and kinesin and dynein motors (Rattner \& Brinkley 1972, Hall et al. 1992, Yoshida et al. 1994, Saade et al. 2007, Hayasaka et al. 2008, Kierszenbaum et al. 2011, Lehti \& Sironen 2016, Zhang et al. 2016). Intriguingly, given that both plus- (kinesin) and minus- (dynein) end directed motors are present on the manchette (Fig. 3E), IMT is likely bidirectional and thus transports proteins from both the apical region and the cytoplasmic lobes to the HTCA. $\beta$-actin- and myosin-based vesicles are also present in the manchette (Mochida et al. 2000, Kierszenbaum et al. 2003a) leading to speculation that F-actin-based transport also contributes to IMT. However, this requires further validation as despite numerous attempts, polymerised actin filaments have never been detected in the manchette (Welch \& O'Rand 1985, Halenda et al. 1987, Kierszenbaum et al. 2003a, Tachibana et al. 2005), and thus, the possibility that the $\beta$-actin detected is instead part of dynactin complexes, which interact with dynein to facilitate microtubulebased transport, cannot be excluded.
Beyond this, little else is known about the mechanisms that regulate the formation of the sperm axoneme and its accessory structures. The formation of the mitochondrial sheath in particular remains unresolved. Mitochondria are observed to assemble into longitudinal rows in the cytoplasm adjacent to the flagella, and upon the distal migration of the annulus, they load onto the flagella ODFs. Of note, a double-helical F-actin scaffold associated with the mid-piece mitochondria has recently been identified. Given that the F-actin arrangement follows the helical arrangement of the mitochondria, it is possible that F-actin-based mechanisms are involved in the compaction of mitochondria around the flagella and/or in the structural integrity of the sheath (Fig. 4A; Gervasi et al. 2018). Microtubules also have a possible role, and indeed, kinesin-facilitated microtubule-based transport of mitochondria occurs in a variety of contexts. In spermatids, kinesin light chain 3 (KLC3) colocalises with mitochondria, and mutant KLC3 appears to disrupt mitochondrial sheath assembly (Zhang et al. 2012). Given that KLC3 is a plus-end-directed motor, it is plausible that transport up the inner surface of manchette microtubules is responsible for 'lining up' the mitochondria prior to their loading on to the ODFs (Fig. 4A).

Typical aspects of microtubule regulation likely also contribute to flagella formation. For example, microtubule-severing proteins have emerged as essential for proper axoneme formation in mice (O'Donnell et al. 2012; Dunleavy et al. 2017). In addition, the axoneme exhibits extensive post-translational modifications, including acetylation, mono-/poly-glutamylation, detyrosination and mono-/poly-glycylation (Gagnon et al. 1996, Kann et al. 1998, Huitorel et al. 2002, Kierszenbaum 2002), and mutations in tubulinmodifying enzymes cause defective axoneme formation and motility (Ikegami \& Setou 2010). Such modifications are thus believed to regulate the formation, stability and function of the axoneme.

\section{Nuclear remodelling}

As spermiogenesis proceeds, the spermatid nucleus undergoes extensive compaction and elongation. This coincides with the formation of the manchette around the distal half of the nucleus (Fig. 3A). Within this structure, microtubules arrange into linear arrays, parallel to the long axis of the nucleus (Rattner \& Brinkley 1972), with their dynamic plus-ends captured and stabilised by a dense tubulin/keratin-9-based perinuclear ring (Mochida et al. 2000, Kato et al. 2004, Dunleavy et al. 2017). In rodents, at its largest, the manchette contains over 1000 microtubules (Rattner \& Brinkley 1972), which form frequent links with adjacent microtubules (Rattner \& Brinkley 1972, MacKinnon \& Abraham 1972) and the nuclear envelope (Russell et al. 1991; Fig. 3C). The manchette is thus extremely rigid 
and appears to exert mechanical force, sculpting the base of the spermatid nucleus as it elongates. Indeed, its role in spermatid nuclear shaping is highlighted by consistent observations that genetically modified mouse models displaying manchette abnormalities also exhibit defects in head morphology (Russell et al. 1991, Mendoza-Lujambio et al. 2002, Zhou et al. 2009, Zhang et al. 2009, Lehti \& Sironen 2016, Dunleavy et al. 2017). Collectively, data suggest that the manchette sculpts and tapers the sperm head using a 'ratchet-like' mechanism, forming progressive connections with the nuclear envelope as it slowly moves down the nucleus in a caudal direction, while progressively reducing its diameter (Fig. 3D; Russell et al. 1991). However, as the composition of the manchette microtubule-microtubule and microtubule-nuclear envelope linkers is yet to be convincingly determined, the actual mechanisms underlying manchette constriction and movement remain unresolved. Immunolocalisation studies have suggested that manchette-nuclear envelope linkers are LINC complexes, composed of SUN4, SUN3 and KASH protein, Nesprin-1 (Göb et al. 2010, Calvi et al. 2015, Pasch et al. 2015, Yeh et al. 2015). Indeed, in other contexts, LINC complexes link the peripheral cytoskeleton to the nucleus and contribute to force transmission across nuclear membranes (Horn 2014). Typically, they comprise a SUN inner nuclear membrane protein, bound to a KASH outer nuclear membrane protein, which can link to microtubule motor proteins (Horn 2014, Kim et al. 2015). Given that microtubule motor proteins are observed at the manchette-nuclear interface (Yoshida et al. 1994), it is plausible that LINCmicrotubule motor protein interactions drive the caudal movement of the manchette. Consistent with this, SUN4 ablation results in the absence of manchette-nuclear linkers, manchette-nucleus detachment and defective sperm head shaping in mice (Calvi et al. 2015, Pasch et al. 2015). However, Nesprin-1-knockout mice are male fertile (Zhang et al. 2007), and of all other known $\mathrm{KASH}$ proteins, only KASH-5, which does not localise to the manchette (Horn et al. 2013), is required for male fertility (Zhang et al. 2007, Horn et al. 2013, Ketema et al. 2013), suggesting interactions between SUN4 and the manchette are mediated by an as yet unidentified mechanism. Of note, during nuclear shaping, the septin cytoskeletal protein, septin-12, is closely associated with the nuclear envelope and is capable of binding LINC complex proteins, including SUN4 (Yeh et al. 2015). Given that several studies have established a role for septin-12 in spermatid nuclear shaping in both rodents and humans (Table 1; Lin et al. 2011, 2012, Kuo et al. 2013), one attractive hypothesis is that septin-12 is the 'missing link' between the manchette and SUN4 during spermatid remodelling.

As for the manchette microtubule-microtubule linkers, their identity is largely speculative. Strikingly similar inter-microtubule connectors, comprising a
TACC3-ch-TOG-clathrin complex, are observed between adjacent kinetochore microtubules during mitosis (Booth et al. 2011, Nixon et al. 2015). Whether similar mechanisms participate in manchette microtubule linkage remain to be investigated. Alternatively, microtubule cross-linking and bundling proteins, such as tau and MAP4, localise to the manchette (Ashman et al. 1992, Parysek et al. 1984), as do the poorly understood tubulins, delta and epsilon (Kato et al. 2004, Dunleavy et al. 2017) which are predicted to associate laterally with microtubule polymers (Inclán \& Nogales 2001). A wide range of MAPs, including microtubule-severing proteins and motor proteins (Dunleavy et al. 2017 and older publications reviewed in Lehti \& Sironen 2016), also contribute to the movement, constriction and eventual dissolution of the manchette. However, the mechanisms by which these proteins regulate manchette dynamics remain unclear.

The acroplaxome also expands during spermatid nuclear remodelling and a model has been proposed to explain its potential role in shaping the posterior half of the sperm head (Kierszenbaum et al. 2004, 2007). In this model, the tensile strength of keratin-5 filaments in the acroplaxome restrains both endogenous (manchette-derived) and exogenous (from an actinbased network within the Sertoli cell, see 'Actinbased structures between Sertoli cells and spermatids' section) forces acting upon the spermatid head, thus preventing abnormal or excessive nuclear deformation (Kierszenbaum et al. 2004, 2007); however, the data for this model at present is largely correlative. The acroplaxome has also been proposed to play an active role in generating the endogenous forces that sculpt the spermatid nucleus (Kierszenbaum et al. 2004). This is due to observations that the marginal ring of the acroplaxome constricts and descends caudally, mimicking the constriction and migration of the subadjacent manchette perinuclear ring. However, in Sun4-knockout mice, wherein the manchette fails to associate with the nucleus, although caudal expansion of the acroplaxome-acrosome complex still occurs, constriction of the acroplaxome marginal ring is not apparent and spermatid heads remain rounded (Calvi et al. 2015). These data instead suggest the reduction in marginal ring diameter is simply a response to, rather than a cause of, the narrowing of the spermatid head.

Similar to acrosome biogenesis, spermatid nuclear remodelling requires an intact IF-based nuclear lamina (Table 1; Shen et al. 2014), likely to provide a strong anchor for the manchette and acroplaxome. As discussed earlier, the acroplaxome appears to be tethered to the nuclear lamina via desmosome-like junctions in the marginal ring (Kierszenbaum et al. 2003b) and LINC complexes appear to link the manchette microtubules (Calvi et al. 2015, Pasch et al. 2015, Yeh et al. 2015), and possibly the acroplaxome (Göb et al. 2010), to the nuclear lamina. Both the desmosome-like junctions and 
LINC complexes are anticipated to be involved in nuclear deformation and thus likely facilitate spermatid nuclear remodelling (Fig. 3E). Similar to meiotic prophase I (see 'Spermatogonia and spermatocytes' section), changes in nuclear lamina composition also facilitate nuclear deformation during spermiogenesis. Spermiogenesis is characterised by the upregulation of spermatid-specific lamin B3, which like the meiosis-specific lamin C2, has a shorter, more flexible, central $\alpha$-helical coil than typical IFs and thus its enrichment reduces stability of the nuclear lamina (Schütz et al. 2005a,b, Elkhatib et al. 2015).

\section{The dynamic Sertoli cell cytoskeleton}

Sertoli cells are the 'nurse' cells of the seminiferous epithelium; they provide the structural framework and physiological environment necessary for effective spermatogenesis. They are polarised, irregularly shaped, columnar epithelial cells that sit on the basement membrane of the seminiferous tubule (Fig. 1). The basal regions of Sertoli cells are 'powerhouses' containing an abundance of organelles. Sertoli cells also have long apical cytoplasmic processes that envelop developing germ cells and, with the exception of cytoskeletal elements and mitochondria, are devoid of organelles. Sertoli cells maintain numerous cytoskeletal-based junctions with germ cells, which both physically tether germ cells into position and contribute to spermatid remodelling (Fig. 1). Moreover, to accommodate and effectuate the structural changes and movements of developing germ cells, Sertoli cell shape is cyclically remodelled. In order to achieve these functions, Sertoli cells possess a dynamic cytoskeleton rich in actin filaments, microtubules and intermediate filaments. The major roles of each of these cytoskeletal structures in Sertoli cells are discussed below.

\section{Actin-based cytoskeleton}

When viewed by microscopy, actin filaments are clearly concentrated in particular areas of the Sertoli cell, most notably at adhesion junctions between Sertoli cells at their base, adjacent to spermatids as they elongate during spermiogenesis and at the site of spermiation, when mature spermatids are released from the Sertoli cell.

\section{Actin-based structures between Sertoli cells}

Large tracts of actin filaments are present at the junction between the basal aspects of adjacent Sertoli cells towards their base, within a structure known as the ectoplasmic specialisation (ES) (Fig. 1). The actin filaments at this site are bundled into hexagonally packed arrays by the protein espin (Bartles et al. 1996). This actin array is sandwiched between the Sertoli cell plasma membrane and a layer of endoplasmic reticulum
(Russell \& Peterson 1985, Vogl et al. 2008). The Sertoli cell membranes contain proteins that mediate tight intercellular adhesion (Hermo et al. 2010). The ES structures at this site are interspersed with other actinrelated adhesion junctions - adherens, gap and tight (occluding) junctions (Fig. 1; Vogl et al. 2014, Stanton 2016). Actin-based tubulobulbar complexes (TBCs) are also present between Sertoli cells at the basal aspect (Fig. 1); these are unique endocytic structures that can internalise junctional structures (Vogl et al. 2014) and are explained in more detail below (see 'Actinbased structures between Sertoli cells and spermatids' section). Thus, ES, TBCs and intercellular adhesion junctions comprise a heterogeneous actin-associated Sertoli cell junctional complex with multiple functions during spermatogenesis.

This junctional complex allows the Sertoli cell to strictly determine the microenvironment of the developing spermatocytes and spermatids. Tight junctions within this complex prevent the free passage of molecules into the adluminal part of the seminiferous tubule (Kaur et al. 2014) ensuring that spermatocytes and spermatids develop within an immunologically privileged and strictly regulated microenvironment. The actin-associated Sertoli cell junctional complex contributes to the function of the so-called blood-testis barrier, which prevents the access of factors and cells from the circulation to the inner part of the tubule and protects the immunogenic developing sperm from the immune system (Mital et al. 2011, Kaur et al. 2014). The Sertoli cell junctional complexes are remodelled during the spermatogenic cycle to allow early spermatocytes to enter the inner compartment of the seminiferous tubule, while maintaining the microenvironment of spermatocytes and spermatids. This remodelling involves various proteins involved in the regulation of $\mathrm{F}$-actin ( $\mathrm{Li}$ et al. 2016) as well as basal TBCs to internalise junctional structures (Vogl et al. 2014) (see next section).

\section{Actin-based structures between Sertoli cells and spermatids}

Immediately prior to elongation, the centrally located spermatid nucleus polarises to one side of the cell and becomes encircled by a Sertoli cell actin-based ES in the region adjacent to the developing acrosome (Fig. 1). This apical ES confers extremely tight adhesion between the Sertoli cell and developing spermatid (Romrell \& Ross 1979) and facilitates movement of spermatids in the epithelium. As these cells begin to elongate, they are enveloped by the Sertoli cell cytoplasm and are pulled towards the base of the epithelium prior to being translocated to the luminal edge in preparation for spermiation. This translocation is facilitated by microtubules interacting with the actin-based apical ES, moving the spermatid basally as it elongates and then apically to the luminal edge prior to its release 
at spermiation (Vogl et al. 2008). The apical ES is also hypothesised to be involved in spermatid nuclear shaping by exerting anchoring forces on the spermatid head as it elongates (Kierszenbaum et al. 2007). However, as actin bundles in the ES are non-contractile (Vogl \& Soucy 1985), it is yet to be determined if this structure actively exerts force to sculpt the spermatid head. Conversely, other Sertoli cell actin-based structures have been more conclusively linked to spermatid head shaping (Fig. 3A). Disruption of a Sertoli cortical F-actin meshwork results in a loss of Sertoli-spermatid adherens junctions containing contractile actomyosin bundles, a concomitant increase in non-contractile ES junctions and notably, defective spermatid head shaping (Sakamoto et al. 2018).

\section{Actin-based structures during spermiation}

During spermiation, the spermatid undergoes its final remodelling and eventual release from the Sertoli cell, prior to its passage to the epididymis, reviewed in O'Donnell et al. (2011). The spermatid is situated at the luminal edge of the epithelium while its extensive cytoplasm is 'stripped off' by the Sertoli cell to reveal the flagellum that will ultimately be capable of motility (Fig. 1). During this process, the spermatid must maintain tight adhesion to the Sertoli cell as it is subjected to the flow of fluid through the seminiferous tubule ( $\mathrm{O}^{\prime}$ Donnell et al. 2011).

At the beginning of spermiation, the spermatid adheres to the Sertoli cell via the apical ES; however, this is gradually removed and replaced by a focal adhesionlike junction (O'Donnell et al. 2011). The removal of the extensive apical ES may involve actin regulatory proteins (Qian et al. 2014). TBCs between spermatids and Sertoli cells have also been shown to remove adhesion proteins consistent with a role in disassembly of the apical ES (O'Donnell et al. 2011, Vogl et al. 2014). Based on these data, TBCs are proposed to internalise both Sertoli cell and spermatid plasma membranes along with associated adhesion proteins and ES structures; these structures then 'bud off' and enter the endocytic pathway within the Sertoli cell cytoplasm (Vogl et al. 2014). Various proteins involved in F-actin dynamics drive TBC formation and dissolution and ES removal (Young et al. 2009, 2012, Vogl et al. 2014) and thus successful spermiation relies on the regulation of actin-based processes. It should be noted, however, that recent data have shown that in the absence of TBC formation in mice, the ES dissembles normally suggesting that additional ES disassembly mechanisms may exist (Dunleavy et al. 2017). Indeed, given that ectopic induction of a matrix metalloproteinase-2 (MMP-2)-dependent proteolytic pathway causes reductions in $\beta 1$-integrin and laminin- $\gamma 3$ of the apical ES and the loss of spermatid-Sertoli cell adhesion (Siu \& Cheng 2004, Yao et al. 2010), it is likely that proteases also contribute to ES disassembly.

\section{Intermediate filament-based cytoskeleton}

In adult Sertoli cells, IFs are present in an extensive cytoplasmic network, arranged around the basally placed nucleus (Fig. 1) and emanate out toward specific regions of plasma membrane (Amlani \& Vogl 1988, Vogl et al. 2008). Sertoli cell IFs are largely vimentin based, in contrast to other epithelia which have predominantly cytokeratin-based filaments (Franke et al. 1979). Sertoli cell IFs terminate in desmosome-like junctions between the basal aspects of Sertoli cells (Fig. 1; Vogl et al. 2008) and participate in the Sertoli cell junctional complex. They also terminate at the Sertoli cell plasma membrane at junctions with specific types of germ cells: for example, IFs transiently associate with the heads of elongating spermatids that are deeply embedded within the seminiferous epithelium (stage II-IV in mice; Amlani $\&$ Vogl 1988). Finally, IFs terminate in hemi-desmosomes between the base of Sertoli cells and the underlying basement membrane (Fig. 1; Vogl et al. 2008).

Despite their extensive networks within Sertoli cells, IFs do not appear to be essential for spermatogenesis. Male mice lacking vimentin are fertile with normal testicular histology, despite an absence of IFs within Sertoli cells, suggesting that the role of Sertoli cell IFs may be largely to provide mechanical stability to the seminiferous epithelium, but this function may not be essential for spermatogenesis, reviewed in (Vogl et al. 2008).

\section{Microtubule-based cytoskeleton}

As is expected of dynamic polarised cells, Sertoli cells have an abundant microtubule cytoskeleton (Vogl et al. 2008). As Sertoli cells remodel their shape to respond to the needs of the developing germ cells, their microtubules reorganise accordingly. The most dramatic variations in microtubule architecture are seen in the apical processes (Vogl et al. 2008). In processes associated with spermatogonia and spermatocytes cells, microtubules are rarely observed. Conversely, microtubules are abundant in Sertoli cells crypts within which spermatids are embedded as they elongate (Fig. 1). During spermatid elongation, microtubules become concentrated in Sertoli cells in regions surrounding the acrosome and show extensions into regions closely associated with the residual cytoplasm of the spermatid. The observed effects of microtubule-disrupting drugs colchicine and vinblastine (Russell et al. 1981, Vogl et al. 1983, Allard et al. 1993) strongly support the hypothesis that Sertoli cell shape changes are driven by microtubule dynamics. In turn, the dynamic nature of Sertoli microtubules is likely driven by tyrosination. Sertoli cells contain a high concentration of tyrosinated microtubules (Hermo et al. 1991, Wenz \& Hess 1998), a post-translational modification associated with high turnover rates (Webster et al. 1987) and is conducive 
to motor-dependent microtubule disassembly (Peris et al. 2009). Moreover, microtubule tyrosination levels fluctuate, consistent with stage-specific changes in Sertoli cell architecture and microtubule organisation (Hermo et al. 1991, Wenz \& Hess 1998).

In a formation typical of polarised cells, Sertoli cell microtubule networks have a linear arrangement, parallel to the longitudinal axis of the cell (Fig. 1; Vogl et al. 2008). In other polarised cells, such as neurons, microtubules are predominantly nucleated from a perinuclear centrosome and subsequently released and transported to distal sites. However, interestingly, Sertoli cell microtubules are nucleated in the cytoplasmic processes towards their apex rather than at the site of the Sertoli cell centrosome near the base of the cell (Vogl et al. 2008). After induced microtubule depolymerisation, new microtubules are first seen in the Sertoli apical processes (Vogl et al. 1995); likewise, overexpression of $\gamma$-tubulin, a key element for de novo microtubule nucleation, results in the accumulation of microtubules in the apex (Fleming et al. 2003). Sertoli cell microtubule minus ends also show no association with the centrosome and are instead uniformly oriented toward the apical cytoplasm (Redenbach \& Vogl 1991).

Microtubule-driven kinetics underlie many Sertoli cell functions during spermatogenesis. As discussed earlier, microtubule networks within Sertoli cells make structural links with actin-based ESs and disruption of Sertoli microtubule dynamics results in the failure of spermatids to translocate to the luminal edge in preparation for spermiation (Russell et al. 1989, Fleming et al. 2003). Taken together, these results support the concept that microtubules, likely in conjunction with dynein and kinesin (Miller et al. 1999, Guttman et al. 2000, Vaid et al. 2007), are used to regulate the position of spermatids within the epithelium via the apical ES (Fig. 1). Following spermatid disengagement, Sertoli cell microtubule networks are also required for translocation of the residual spermatid cytoplasm to the basal surface of the seminiferous tubule lumen (Russell et al. 1989, Fleming et al. 2003). As residual body phagocytosis typically occurs at the basal region, failure of translocation can prevent residual body elimination. Another key function of microtubules within Sertoli cells is the maintenance of seminiferous epithelium structural integrity. Disruption of microtubule dynamics in Sertoli cells results in a loss of lateral stability and premature shedding of developing germ cells (Russell et al. 1981).

\section{Remaining questions and future directions}

The seminiferous epithelium is an extraordinarily complex and dynamic epithelium, accompanied by equally extraordinary and dynamic cytoskeletal changes. A variety of actin-, microtubule- and intermediate filament-based structures enable the Sertoli cell to modify its shape as it responds to the changing complement of germ cells and to control intercellular adhesion at multiple sites simultaneously. Germ cells, too, rely on unique and complex cytoskeletal dynamics to facilitate their development from a round, diploid cell into a haploid, highly specialised spermatozoon. While significant advances in understanding the nature and complexity of these cytoskeletal elements during spermatogenesis have been made, the picture is far from complete. As highlighted throughout this review a number of questions remain, particularly in relation to spermiogenesis. Despite being first described over 60 years ago, the ultrastructure and regulation of the manchette remains poorly understood. Given this structure's role in spermatid head shaping, and the fact that sperm head abnormalities are frequently observed in conditions of infertility, elucidating its structure and function is of clinical relevance. In particular, the identification of the manchette inter-microtubule and microtubule-nuclear linkers is necessary to understand manchette constriction and descent. Indeed, the current LINC complex models of cytoskeletal-nuclear attachment in spermatids are incomplete as they ignore data showing that the proposed KASH domains of these complexes are not required for male fertility. The role of actin in the manchette is also unclear; whether it is present in filamentous form and participates in the transport of myosin-VA-associated vesicles needs to be verified. Likewise, the mysterious process of mitochondrial sheath assembly requires attention, particularly as mitochondrial sheath defects are associated with sterility in mice. Compared to lower order species such as Drosophila, there are limited data on the assembly, dynamics and regulation of the male meiotic spindle, and similarly our current understanding of basal body dynamics relies heavily on data from somatic cells.

Most importantly, the robustness of many of the major hypotheses in the field is undermined by the fact they are based on predominantly observational studies of fixed tissues and cells. The roles of many motor proteins are presumed based on their localisation. For example, due to its presence in the acroplaxome, myosin- $\mathrm{Va}$ is proposed to facilitate acrosomal spreading; however, no functional data exist to prove this. Moving forward, live imaging studies can provide enhanced insights into dynamic cytoskeletal processes important during spermatogenesis. Given the increasing availability of excellent live cytoskeletal stains compatible with both confocal and super resolution microscopy techniques, such studies are increasingly feasible and their adoption will be integral to the continued advancement of the field. The advent of technologies such as CRISPR will also presumably contribute to the generation of functional data to prove many of the proposed mechanisms. 


\section{Declaration of interest}

The authors declare that there is no conflict of interest that could be perceived as prejudicing the impartiality of this review.

\section{Funding}

This work was supported in part by funding from the National Health and Medical Research Council of Australia to M K O'B (APP1058356) and P G S (APP1124606 and APP1099002) and the Australian Research Council to M K O'B (DP160100647).

\section{Acknowledgement}

The authors wish to thank D Jo Merriner for technical assistance.

\section{References}

Akhmanova A \& Steinmetz MO 2015 Control of microtubule organization and dynamics: two ends in the limelight. Nature Reviews Molecular Cell Biology 16 711. (https://doi.org/10.1038/nrm4084)

Allard EK, Johnson KJ \& Boekelheide K 1993 Colchicine disrupts the cytoskeleton of rat testis seminiferous epithelium in a stage-dependent manner. Biology of Reproduction 48 143-153. (https://doi.org/10.1095/ biolreprod48.1.143)

Alsheimer M, Von Glasenapp E, Hock R \& Benavente R 1999 Architecture of the nuclear periphery of rat pachytene spermatocytes: distribution of nuclear envelope proteins in relation to synaptonemal complex attachment sites. Molecular Biology of the Cell 10 1235-1245. (https:// doi.org/10.1091/mbc.10.4.1235)

Amlani S \& Vogl A 1988 Changes in the distribution of microtubules and intermediate filaments in mammalian Sertoli cells during spermatogenesis. Anatomical Record 220 143-160. (https://doi. org/10.1002/ar.1092200206)

Antoniades I, Stylianou P \& Skourides PA 2014 Making the connection: ciliary adhesion complexes anchor basal bodies to the actin cytoskeleton. Developmental Cell 28 70-80. (https://doi.org/10.1016/j. devcel.2013.12.003)

Ashman JB, Hall ES, Eveleth J \& Boekelheide K 1992 Tau, the neuronal heatstable microtubule-associated protein, is also present in the cross-linked microtubule network of the testicular spermatid manchette. Biology of Reproduction 46 120-129. (https://doi.org/10.1095/biolreprod46.1.120)

Bartles JR, Wierda A \& Zheng L 1996 Identification and characterization of espin, an actin-binding protein localized to the F-actin-rich junctional plaques of Sertoli cell ectoplasmic specializations. Journal of Cell Science 109 (Pt 6) 1229-1239.

Basto R, Lau J, Vinogradova T, Gardiol A, Woods CG, Khodjakov A \& Raff JW 2006 Flies without centrioles. Cell 125 1375-1386. (https://doi. org/10.1016/j.cell.2006.05.025)

Berruti G \& Paiardi C 2015 USP8/UBPy-regulated sorting and the development of sperm acrosome: the recruitment of MET. Reproduction 149 633-644. (https://doi.org/10.1530/REP-14-0671)

Berruti G, Ripolone M \& Ceriani M 2010 USP8, a regulator of endosomal sorting, is involved in mouse acrosome biogenesis through interaction with the spermatid ESCRT-0 complex and microtubules. Biology of Reproduction 82 930-939. (https://doi.org/10.1095/biolreprod.109.081679)

Booth DG, Hood FE, Prior IA \& Royle SJ 2011 A TACC3/ch-TOG/clathrin complex stabilises kinetochore fibres by inter-microtubule bridging. EMBO Journal 30 906-919. (https://doi.org/10.1038/emboj.2011.15)

Calvi A, Wong ASW, Wright G, Wong ESM, Loo TH, Stewart CL \& Burke B 2015 SUN4 is essential for nuclear remodeling during mammalian spermiogenesis. Developmental Biology 407 321-330. (https://doi. org/10.1016/j.ydbio.2015.09.010)

Carlomagno G, Van Bragt MPA, Korver CM, Repping S, De Rooij DG \& Van Pelt AMM 2010 BMP4-induced differentiation of a rat spermatogonial stem cell line causes changes in its cell adhesion properties.
Biology of Reproduction 83 742-749. (https://doi.org/10.1095/ biolreprod.110.085456)

Cenci G, Bonaccorsi S, Pisano C, Verni F \& Gatti M 1994 Chromatin and microtubule organization during premeiotic, meiotic and early postmeiotic stages of Drosophila melanogaster spermatogenesis. Journal of Cell Science 107 3521-3534.

Dawe HR, Farr H \& Gull K 2007 Centriole/basal body morphogenesis and migration during ciliogenesis in animal cells. Journal of Cell Science $\mathbf{1 2 0}$ 7-15. (https://doi.org/10.1242/jcs.03305)

Dunleavy JE, Okuda H, O'connor AE, Merriner DJ, O'donnell L, Jamsai D, Bergmann M \& O'bryan MK 2017 Katanin-like 2 (KATNAL2) functions in multiple aspects of haploid male germ cell development in the mouse. PLOS Genetics 13 e1007078. (https://doi.org/10.1371/journal.pgen.1007078)

Dutcher SK 2001 The tubulin fraternity: alpha to eta. Current Opinion in Cell Biology 13 49-54. (https://doi.org/10.1016/S09550674(00)00173-3)

Elkhatib R, Longepied G, Paci M, Achard V, Grillo J-M, Levy N, Mitchell MJ \& Metzler-Guillemain C 2015 Nuclear envelope remodelling during human spermiogenesis involves somatic B-type lamins and a spermatidspecific B3 lamin isoform. Molecular Human Reproduction 21 225-236. (https://doi.org/10.1093/molehr/gau111)

Elkis Y, Bel S, Rahimi R, Lerer-Goldstein T, Levin-Zaidman S, Babushkin T, Shpungin S \& Nir U 2015 TMF/ARA160 governs the dynamic spatial orientation of the golgi apparatus during sperm development. PLOS ONE 10 e0145277. (https://doi.org/10.1371/journal.pone.0145277)

Fawcett DW 1975 The mammalian spermatozoon. Developmental Biology 44 394-436. (https://doi.org/10.1016/0012-1606(75)90411-X)

Fawcett DW \& Phillips DM 1969 The fine structure and development of the neck region of the mammalian spermatozoon. Anatomical Record $\mathbf{1 6 5}$ 153-183. (https://doi.org/10.1002/ar.1091650204)

Fishman EL, Jo K, Nguyen QPH, Kong D, Royfman R, Cekic AR, Khanal S, Miller AL, Simerly C, Schatten G et al. 2018 A novel atypical sperm centriole is functional during human fertilization. Nature Communications 9 2210. (https://doi.org/10.1038/s41467-018-04678-8)

Fleming SL, Shank PR \& Boekelheide K $2003 \gamma$-tubulin overexpression in Sertoli cells in vivo. II: retention of spermatids, residual bodies, and germ cell apoptosis. Biology of Reproduction 69 322-330. (https://doi. org/10.1095/biolreprod.102.011817)

Franke WW, Grund C \& Schmid E 1979 Intermediate-sized filaments present in Sertoli cells are of the vimentin type. European Journal of Cell Biology 19 269-275. (https://doi.org/10.1016/B978-0-12-8001806.00007-4)

Fung KY, Dai L \& Trimble WS 2014 Cell and molecular biology of septins. International Review of Cell and Molecular Biology 310 289-339.

Gagnon C, White D, Cosson J, Huitorel $P$, Eddé $B$, Desbruyères $E$, PaturleLafanechère L, Multigner L, Job D \& Cibert C 1996 The polyglutamylated lateral chain of alpha-tubulin plays a key role in flagellar motility. Journal of Cell Science 109 1545-1553.

Gervasi MG, Xu X, Carbajal-Gonzalez B, Buffone MG, Visconti PE \& Krapf D 2018 The actin cytoskeleton of the mouse sperm flagellum is organized in a helical structure. Journal of Cell Science 131. (https://doi. org/10.1242/jcs.215897)

Giansanti MG, Bucciarelli E, Bonaccorsi S \& Gatti M 2008 Drosophila SPD-2 is an essential centriole component required for PCM recruitment and astral-microtubule nucleation. Current Biology 18 303-309. (https:// doi.org/10.1016/j.cub.2008.01.058)

Gibbons B \& Gibbons I 1973 The effect of partial extraction of dynein arms on the movement of reactivated sea-urchin sperm. Journal of Cell Science 13 337-357.

Göb E, Schmitt J, Benavente R \& Alsheimer M 2010 Mammalian sperm head formation involves different polarization of two novel LINC complexes. PLOS ONE 5 e12072. (https://doi.org/10.1371/journal. pone.0012072)

Greenbaum MP, Ma L \& Matzuk MM 2007 Conversion of midbodies into germ cell intercellular bridges. Developmental Biology 305 389-396. (https://doi.org/10.1016/j.ydbio.2007.02.025)

Guttman JA, Kimel GH \& Vogl AW 2000 Dynein and plus-end microtubuledependent motors are associated with specialized Sertoli cell junction plaques (ectoplasmic specializations). Journal of Cell Science $\mathbf{1 1 3}$ 2167-2176.

Haglund K, Nezis IP \& Stenmark H 2011 Structure and functions of stable intercellular bridges formed by incomplete cytokinesis during 
development. Communicative and Integrative Biology 4 1-9. (https:// doi.org/10.4161/cib.4.1.13550)

Halenda RM, Primakoff P \& Myles DG 1987 Actin filaments, localized to the region of the developing acrosome during early stages, are lost during later stages of guinea pig spermiogenesis. Biology of Reproduction $\mathbf{3 6}$ 491-499. (https://doi.org/10.1095/biolreprod36.2.491)

Hall ES, Eveleth J, Jiang C, Redenbach DM \& Boekelheide K 1992 Distribution of the microtubule-dependent motors cytoplasmic dynein and kinesin in rat testis. Biology of Reproduction 46 817-828. (https:// doi.org/10.1095/biolreprod46.5.817)

Hayasaka S, Terada Y, Suzuki K, Murakawa H, Tachibana I, Sankai T, Murakami T, Yaegashi N \& Okamura K 2008 Intramanchette transport during primate spermiogenesis: expression of dynein, myosin $\mathrm{Va}$, motor recruiter myosin Va, VIla-Rab27a/b interacting protein, and Rab27b in the manchette during human and monkey spermiogenesis. Asian Journal of Andrology 10 561-568. (https://doi.org/10.1111/j.17457262.2008.00392.x)

Hermo L, Oko R \& Hecht N 1991 Differential post-translational modifications of microtubules in cells of the seminiferous epithelium of the rat: a light and electron microscope immunocytochemical study. Anatomical Record 229 31-50. (https://doi.org/10.1002/ar.1092290106)

Hermo L, Pelletier RM, Cyr DG \& Smith CE 2010 Surfing the wave, cycle, life history, and genes/proteins expressed by testicular germ cells. Part 5: intercellular junctions and contacts between germs cells and Sertoli cells and their regulatory interactions, testicular cholesterol, and genes/proteins associated with more than one germ cell generation. Microscopy Research and Technique 73 409-494. (https://doi.org/10.1002/jemt.20787)

Horn HF 2014 LINC complex proteins in development and disease. Current Topics in Developmental Biology 109 287-321. (https://doi.org/10.1016/ B978-0-12-397920-9.00004-4)

Horn HF, Kim DI, Wright GD, Wong ESM, Stewart CL, Burke B \& Roux KJ 2013 A mammalian KASH domain protein coupling meiotic chromosomes to the cytoskeleton. Journal of Cell Biology 202 1023-1039. (https://doi.org/10.1083/jcb.201304004)

Hubbert C, Guardiola A, Shao R, Kawaguchi Y, Ito A, Nixon A, Yoshida M, Wang X-F \& Yao T-P 2002 HDAC6 is a microtubule-associated deacetylase. Nature 417 455. (https://doi.org/10.1038/417455a)

Huitorel P, White D, Fouquet JP, Kann ML, Cosson J \& Gagnon C 2002 Differential distribution of glutamylated tubulin isoforms along the sea urchin sperm axoneme. Molecular Reproduction and Development 62 139-148. (https://doi.org/10.1002/mrd.10086)

Ihara M, Kinoshita A, Yamada S, Tanaka H, Tanigaki A, Kitano A, Goto M, Okubo K, Nishiyama H \& Ogawa O 2005 Cortical organization by the septin cytoskeleton is essential for structural and mechanical integrity of mammalian spermatozoa. Developmental Cell 8 343-352. (https://doi. org/10.1016/j.devcel.2004.12.005)

Ikegami K \& Setou M 2010 Unique post-translational modifications in specialized microtubule architecture. Cell Structure and Function 35 15-22. (https://doi.org/10.1247/csf.09027)

Inclán YF \& Nogales E 2001 Structural models for the self-assembly and microtubule interactions of gamma-, delta- and epsilon-tubulin. Journal of Cell Science 114 413-422.

Jahn D, Schramm S, Benavente R \& Alsheimer M 2010 Dynamic properties of meiosis-specific lamin C2 and its impact on nuclear envelope integrity. Nucleus 1 273-283. (https://doi.org/10.4161/nucl.11800)

Janke C 2014 The tubulin code: molecular components, readout mechanisms, and functions. Journal of Cell Biology 206 461-472. (https://doi.org/10.1083/jcb.201406055)

Johnson KA \& Rosenbaum JL 1992 Polarity of flagellar assembly in Chlamydomonas. Journal of Cell Biology 119 1605-1611. (https://doi. org/10.1083/jcb.119.6.1605)

Kallio M, Mustalahti T, Yen TJ \& Lähdetie J 1998 Immunolocalization of $\alpha$-tubulin, $\gamma$-tubulin, and CENP-E in male rat and male mouse meiotic divisions: pathway of meiosis I spindle formation in mammalian spermatocytes. Developmental Biology 195 29-37. (https://doi. org/10.1006/dbio.1997.8822)

Kanatsu-Shinohara M, Takehashi M, Takashima S, Lee J, Morimoto $H$, Chuma S, Raducanu A, Nakatsuji N, Fassler R \& Shinohara T 2008 Homing of mouse spermatogonial stem cells to germline niche depends on beta1-integrin. Cell Stem Cell 3 533-542. (https://doi.org/10.1016/j. stem.2008.08.002)
Kann ML, Prigent Y, Levilliers N, Bré MH \& Fouquet JP 1998 Expression of glycylated tubulin during the differentiation of spermatozoa in mammals. Cell Motility and the Cytoskeleton 41 341-352. (https://doi.org/10.1002/ (SICI)1097-0169(1998)41:4<341::AID-CM6>3.0.CO;2-8)

Kato A, Nagata Y \& Todokoro K $2004 \delta$-tubulin is a component of intercellular bridges and both the early and mature perinuclear rings during spermatogenesis. Developmental Biology 269 196-205. (https:// doi.org/10.1016/j.ydbio.2004.01.026)

Kaur G, Thompson LA \& Dufour JM 2014 Sertoli cells - immunological sentinels of spermatogenesis. Seminars in Cell and Developmental Biology 30 36-44. (https://doi.org/10.1016/j.semcdb.2014.02.011)

Kefei Y, Pawel G, Andreas M \& Sigrid H-F 2014 Haplo-deficiency of ODF1/ HSPB10 in mouse sperm causes relaxation of head-to-tail linkage. Reproduction 148 499-506. (https://doi.org/10.1530/REP-14-0370)

Ketema M, Kreft M, Secades P, Janssen H \& Sonnenberg A 2013 Nesprin-3 connects plectin and Vimentin to the nuclear envelope of Sertoli cells but is not required for Sertoli cell function in spermatogenesis. Molecular Biology of the Cell 24 2454-2466. (https://doi.org/10.1091/mbc.e13-020100)

Kierszenbaum AL 2002 Intramanchette transport (IMT): managing the making of the spermatid head, centrosome, and tail. Molecular Reproduction and Development 63 1-4. (https://doi.org/10.1002/ mrd.10179)

Kierszenbaum A, Rivkin E \& Tres LL 2003a The actin-based motor myosin $\mathrm{Va}$ is a component of the acroplaxome, an acrosome-nuclear envelope junctional plate, and of manchette-associated vesicles. Cytogenetic and Genome Research 103 337-344. (https://doi.org/10.1159/000076822)

Kierszenbaum AL, Rivkin E \& Tres LL 2003b Acroplaxome, an F-actinkeratin-containing plate, anchors the acrosome to the nucleus during shaping of the spermatid head. Molecular Biology of the Cell $\mathbf{1 4}$ 4628-4640. (https://doi.org/10.1091/mbc.e03-04-0226)

Kierszenbaum AL, Tres LL, Rivkin E, Kang-Decker N \& Van Deursen JM 2004 The acroplaxome is the docking site of Golgi-derived myosin Va/ Rab27a/b-containing proacrosomal vesicles in wild-type and Hrb mutant mouse spermatids. Biology of Reproduction 70 1400-1410. (https://doi. org/10.1095/biolreprod.103.025346)

Kierszenbaum AL, Rivkin E \& Tres LL 2007 Molecular biology of sperm head shaping. Society of Reproduction and Fertility Supplement 6533.

Kierszenbaum AL, Rivkin E, Tres LL, Yoder BK, Haycraft CJ, Bornens M \& Rios RM 2011 GMAP210 and IFT88 are present in the spermatid golgi apparatus and participate in the development of the acrosomeacroplaxome complex, head-tail coupling apparatus and tail. Developmental Dynamics 240 723-736. (https://doi.org/10.1002/ dvdy.22563)

Kim DI, Birendra KC \& Roux KJ 2015 Making the LINC: SUN and KASH protein interactions. Biological Chemistry 396 295-310. (https://doi. org/10.1515/hsz-2014-0267)

Kissel H, Georgescu M-M, Larisch S, Manova K, Hunnicutt GR \& Steller H 2005 The Sept4 septin locus is required for sperm terminal differentiation in mice. Developmental Cell 8 353-364. (https://doi.org/10.1016/j. devcel.2005.01.021)

Köster S, Weitz D, Goldman RD, Aebi U \& Herrmann H 2015 Intermediate filament mechanics in vitro and in the cell: from coiled coils to filaments, fibers and networks. Current Opinion in Cell Biology 0 82-91. (https:// doi.org/10.1016/j.ceb.2015.01.001)

Kuo P-L, Chiang H-S, Wang Y-Y, Kuo Y-C, Chen M-F, Yu I, Teng Y-N, Lin S-W \& Lin Y-H 2013 SEPT12-microtubule complexes are required for sperm head and tail formation. International Journal of Molecular Sciences 14 22102-22116. (https://doi.org/10.3390/ijms141122102)

Kwitny S, Klaus AV \& Hunnicutt GR 2010 The annulus of the mouse sperm tail is required to establish a membrane diffusion barrier that is engaged during the late steps of spermiogenesis. Biology of Reproduction 82 669-678. (https://doi.org/10.1095/biolreprod.109.079566)

Lagos-Cabré R \& Moreno RD 2008 Mitotic, but not meiotic, oriented cell divisions in rat spermatogenesis. Reproduction 135 471-478.

Lattao R, Bonaccorsi S \& Gatti M 2012 Giant meiotic spindles in males from Drosophila species with giant sperm tails. Journal of Cell Science 125 584-588. (https://doi.org/10.1242/jcs.101469)

Lehti MS \& Sironen A 2016 Formation and function of manchette and flagellum during spermatogenesis. Reproduction 151 R43-R54. (https:// doi.org/10.1530/REP-15-0310) 
Li Z, Pan C-Y, Zheng B-H, Xiang L \& Yang W-X 2010 Immunocytochemical studies on the acroframosome during spermiogenesis of the caridean shrimp Macrobrachium nipponense (Crustacea, Natantia). Invertebrate Reproduction and Development 54 121-131. (https://doi.org/10.1080/ 07924259.2010.9652324)

Li N, Tang El \& Cheng CY 2016 Regulation of blood-testis barrier by actin binding proteins and protein kinases. Reproduction 151 R29-R41. (https://doi.org/10.1530/REP-15-0463)

Lin Y-H, Chou C-K, Hung Y-C, Yu I-S, Pan H-A, Lin S-W \& Kuo P-L 2011 SEPT12 deficiency causes sperm nucleus damage and developmental arrest of preimplantation embryos. Fertility and Sterility 95 363-365. (https://doi.org/10.1016/j.fertnstert.2010.07.1064)

Lin Y-H, Wang Y-Y, Chen H-I, Kuo Y-C, Chiou Y-W, Lin H-H, Wu C-M, Hsu C-C, Chiang H-S \& Kuo P-L 2012 SEPTIN12 genetic variants confer susceptibility to teratozoospermia. PLOS ONE 7 e34011. (https://doi. org/10.1371/journal.pone.0034011)

Lindemann CB \& Lesich KA 2016 Functional anatomy of the mammalian sperm flagellum. Cytoskeleton 73 652-669. (https://doi.org/10.1002/ cm.21338)

Link J, Jahn D, Schmitt J, Göb E, Baar J, Ortega S, Benavente R \& Alsheimer $\mathbf{M} 2013$ The meiotic nuclear lamina regulates chromosome dynamics and promotes efficient homologous recombination in the mouse. PLOS Genetics 9 e1003261. (https://doi.org/10.1371/journal. pgen.1003261)

Liu X, Kapoor TM, Chen JK \& Huse M 2013 Diacylglycerol promotes centrosome polarization in T cells via reciprocal localization of dynein and myosin II. PNAS 110 11976-11981. (https://doi.org/10.1073/ pnas.1306180110)

Liu H, Li W, Zhang Y, Zhang Z, Shang X, Zhang L, Zhang S, Li Y, Somoza AV, Delpi B et al. 2017 IFT25, an intraflagellar transporter protein dispensable for ciliogenesis in somatic cells, is essential for sperm flagella formation. Biology of Reproduction 96 993-1006. (https:// doi.org/10.1093/biolre/iox029)

Lo JCY, Jamsai D, O'connor AE, Borg C, Clark BJ, Whisstock JC, Field MC, Adams V, Ishikawa T, Aitken RJ et al. 2012 RAB-like 2 has an essential role in male fertility, sperm intra-flagellar transport, and tail assembly. PLOS Genetics 8 e1002969. (https://doi.org/10.1371/journal.pgen.1002969)

Luo J, Rodriguez-Sosa JR, Tang L, Bondareva A, Megee S \& Dobrinski I 2010 Expression pattern of acetylated $\alpha$-tubulin in porcine spermatogonia. Molecular Reproduction and Development 77 348-352. (https://doi. org/10.1002/mrd.21153)

MacKinnon E \& Abraham J 1972 The manchette in stage 14 rat spermatids: a possible structural relationship with the redundant nuclear envelope. Zeitschrift für Zellforschung und Mikroskopische Anatomie 124 1-11.

Maldonado-Báez L, Cole NB, Krämer H \& Donaldson JG 2013 Microtubule-dependent endosomal sorting of clathrin-independent cargo by Hook1. Journal of Cell Biology 201 233-247. (https://doi. org/10.1083/jcb.201208172)

Mendoza-Lujambio I, Burfeind P, Dixkens C, Meinhardt A, HoyerFender S, Engel W \& Neesen J 2002 The Hook1 gene is non-functional in the abnormal spermatozoon head shape (azh) mutant mouse. Human Molecular Genetics 11 1647-1658. (https://doi.org/10.1093/ hmg/11.14.1647)

Miller MG, Mulholland DJ \& Vogl AW 1999 Rat testis motor proteins associated with spermatid translocation (dynein) and spermatid flagella (kinesin-II). Biology of Reproduction 60 1047-1056. (https://doi. org/10.1095/biolreprod60.4.1047)

Mital P, Hinton B \& Dufour J 2011 The blood-testis and blood-epididymis barriers are more than just their tight junctions. Seminars in Cell and Developmental Biology 84 851-858. (https://doi.org/10.1095/ biolreprod.110.087452)

Mochida K, Rivkin E, Gil M \& Kierszenbaum AL 2000 Keratin 9 is a component of the perinuclear ring of the manchette of rat spermatids. Developmental Biology 227 510-519. (https://doi.org/10.1006/ dbio.2000.9911)

Mora-Bermúdez F, Matsuzaki F \& Huttner WB 2014 Specific polar subpopulations of astral microtubules control spindle orientation and symmetric neural stem cell division. elife 3 e02875. (https://doi. org/10.7554/eLife.02875)

Moreno RD, Palomino J \& Schatten G 2006 Assembly of spermatid acrosome depends on microtubule organization during mammalian spermiogenesis. Developmental Biology 293 218-227. (https://doi. org/10.1016/j.ydbio.2006.02.001)

Morimoto A, Shibuya H, Zhu X, Kim J, Ishiguro K-I, Han M \& Watanabe Y 2012 A conserved KASH domain protein associates with telomeres, SUN1, and dynactin during mammalian meiosis. Journal of Cell Biology 198 165-172. (https://doi.org/10.1083/jcb.201204085)

Morrison SJ \& Kimble J 2006 Asymmetric and symmetric stem-cell divisions in development and cancer. Nature 441 1068. (https://doi. org/10.1038/nature04956)

Mostowy S \& Cossart P 2012 Septins: the fourth component of the cytoskeleton. Nature Reviews Molecular Cell Biology 13 183. (https:// doi.org/10.1038/nrm3284)

Nilsen A, Fusser M, Greggains G, Fedorcsak P \& Klungland A 2014 ALKBH4 depletion in mice leads to spermatogenic defects. PLOS ONE 9 e105113. (https://doi.org/10.1371/journal.pone.0105113)

Nixon FM, Gutiérrez-Caballero C, Hood FE, Booth DG, Prior IA \& Royle SJ 2015 The mesh is a network of microtubule connectors that stabilizes individual kinetochore fibers of the mitotic spindle. elife 4 e07635. (https://doi.org/10.7554/eLife.07635)

O'Donnell L, Nicholls PK, O'Bryan MK, Mclachlan RI \& Stanton PG 2011 Spermiation: the process of sperm release. Spermatogenesis 114. (https://doi.org/10.4161/spmg.1.1.14525)

O'Donnell L, Rhodes D, Smith SJ, Merriner DJ, Clark BJ, Borg C, Whittle B, O'Connor AE, Smith LB \& Mcnally FJ 2012 An essential role for katanin p80 and microtubule severing in male gamete production. PLoS Genetics 8 e1002698. (https://doi.org/10.1371/journal.pgen.1002698)

O'Donnell L \& O'Bryan MK 2014 Microtubules and spermatogenesis. Seminars in Cell and Developmental Biology 30 45-54. (https://doi. org/10.1016/j.semcdb.2014.01.003)

Oakley BR, Paolillo V \& Zheng Y $2015 \gamma$-tubulin complexes in microtubule nucleation and beyond. Molecular Biology of the Cell 26 2957-2962. (https://doi.org/10.1091/mbc.E14-11-1514)

Park TJ, Mitchell BJ, Abitua PB, Kintner C \& Wallingford JB 2008 Dishevelled controls apical docking and planar polarization of basal bodies in ciliated epithelial cells. Nature Genetics 40 871-879. (https:// doi.org/10.1038/ng.104)

Parysek LM, Wolosewick JJ \& Olmsted J 1984 MAP 4: a microtubuleassociated protein specific for a subset of tissue microtubules. Journal of Cell Biology 99 2287-2296. (https://doi.org/10.1083/jcb.99.6.2287)

Pasch E, Link J, Beck C, Scheuerle S \& Alsheimer M 2015 The LINC complex component Sun4 plays a crucial role in sperm head formation and fertility. Biology Open 4 1792-1802. (https://doi.org/10.1242/ bio.015768)

Peris L, Wagenbach M, Lafanechère L, Brocard J, Moore AT, Kozielski F, Job D, Wordeman L \& Andrieux A 2009 Motor-dependent microtubule disassembly driven by tubulin tyrosination. Journal of Cell Biology $\mathbf{1 8 5}$ 1159-1166. (https://doi.org/10.1083/jcb.200902142)

Perrin BJ \& Ervasti JM 2010 The actin gene family: function follows isoform. Cytoskeleton 67 630-634. (https://doi.org/10.1002/cm.20475)

Pollard TD 2016 Actin and actin-binding proteins. Cold Spring Harbor Perspectives in Biology $\mathbf{1 0}$ a018226. (https://doi.org/10.1101/ cshperspect.a018226)

Qian X, Mruk DD, Cheng YH, Tang El, Han D, Lee WM, Wong EW \& Cheng CY 2014 Actin binding proteins, spermatid transport and spermiation. Seminars in Cell and Developmental Biology 30 75-85. (https://doi.org/10.1016/j.semcdb.2014.04.018)

Rattner JB \& Brinkley BR 1972 Ultrastructure of mammalian spermiogenesis: III. The organization and morphogenesis of the manchette during rodent spermiogenesis. Journal of Ultrastructure Research 41 209-218. (https:// doi.org/10.1016/S0022-5320(72)90065-2)

Redenbach D \& Vogl A 1991 Microtubule polarity in Sertoli cells: a model for microtubule-based spermatid transport. European Journal of Cell Biology 54 277-290.

Riparbelli MG \& Callaini G 2011 Male gametogenesis without centrioles. Developmental Biology $349 \quad 427-439 . \quad$ (https://doi.org/10.1016/j. ydbio.2010.10.021)

Romrell LJ \& Ross MH 1979 Characterization of Sertoli cell-germ cell junctional specializations in dissociated testicular cells. Anatomical Record 193 23-41. (https://doi.org/10.1002/ar.1091930103)

Rosenbaum JL \& Witman GB 2002 Intraflagellar transport. Nature Reviews Molecular Cell Biology 3 813-825. (https://doi.org/10.1038/nrm952) 
Russell LD \& Peterson RN 1985 Sertoli cell junctions: morphological and functional correlates. International Review of Cytology 94 177-211.

Russell LD, Malone JP \& Maccurdy D 1981 Effect of the microtubule disrupting agents, colchicine and vinblastine, on seminiferous tubule structure in the rat. Tissue and Cell 13 349-367. (https://doi. org/10.1016/0040-8166(81)90010-0)

Russell LD, Vogl AW \& Weber JE 1987 Actin localization in male germ cell intercellular bridges in the rat and ground squirrel and disruption of bridges by cytochalasin D. Developmental Dynamics 180 25-40. (https://doi.org/10.1002/aja.1001800103)

Russell L, Saxena N \& Turner T 1989 Cytoskeletal involvement in spermiation and sperm transport. Tissue and Cell 21 361-379. (https:// doi.org/10.1016/0040-8166(89)90051-7)

Russell LD, Russell JA, Macgregor GR \& Meistrich ML 1991 Linkage of manchette microtubules to the nuclear envelope and observations of the role of the manchette in nuclear shaping during spermiogenesis in rodents. American Journal of Anatomy 192 97-120. (https://doi. org/10.1002/aja.1001920202)

Saade M, Irla M, Govin J, Victorero G, Samson M \& Nguyen C 2007 Dynamic distribution of Spatial during mouse spermatogenesis and its interaction with the kinesin KIF17b. Experimental Cell Research 313 614-626. (https://doi.org/10.1016/j.yexcr.2006.11.011)

Sakamoto S, Thumkeo D, Ohta H, Zhang Z, Huang S, Kanchanawong P, Fuu T, Watanabe S, Shimada K, Fujihara Y et al. $2018 \mathrm{mDia} 1 / 3$ generate cortical F-actin meshwork in Sertoli cells that is continuous with contractile F-actin bundles and indispensable for spermatogenesis and male fertility. PLoS Biology 16 e2004874. (https://doi.org/10.1371/ journal.pbio.2004874)

Satir P 1968 Studies on cilia III. Further studies on the cilium tip and a "sliding filament" model of ciliary motility. Journal of Cell Biology 39 77-94. (https://doi.org/10.1083/jcb.39.1.77)

Schütz W, Alsheimer M, Öllinger R \& Benavente R 2005a Nuclear envelope remodeling during mouse spermiogenesis: postmeiotic expression and redistribution of germline lamin B3. Experimental Cell Research 307 285-291. (https://doi.org/10.1016/j.yexcr.2005.03.023)

Schütz W, Benavente R \& Alsheimer M 2005b Dynamic properties of germ line-specific lamin B3: the role of the shortened rod domain. European Journal of Cell Biology 84 649-662. (https://doi.org/10.1016/j. ejcb.2005.03.001)

Schwayer C, Sikora M, Slováková J, Kardos R \& Heisenberg C-P 2016 Actin rings of power. Developmental Cell 37 493-506. (https://doi. org/10.1016/j.devcel.2016.05.024)

Shang Y, Zhu F, Wang L, Ouyang Y-C, Dong M-Z, Liu C, Zhao H, Cui X, Ma D, Zhang Z et al. 2017 Essential role for SUN5 in anchoring sperm head to the tail. eLife 6 e28199. (https://doi.org/10.7554/eLife.28199)

Shen J, Chen W, Shao B, Qi Y, Xia Z, Wang F, Wang L, Guo X, Huang X \& Sha J 2014 Lamin A/C proteins in the spermatid acroplaxome are essential in mouse spermiogenesis. Reproduction 148 479-487. (https:// doi.org/10.1530/REP-14-0012)

Sillibourne JE, Hurbain I, Grand-Perret T, Goud B, Tran P \& Bornens M 2013 Primary ciliogenesis requires the distal appendage component Cep123. Biology Open 2 535-545. (https://doi.org/10.1242/bio.20134457)

Siu MKY \& Cheng CY 2004 Interactions of proteases, protease inhibitors, and the $\beta 1$ integrin/laminin $\gamma 3$ protein complex in the regulation of ectoplasmic specialization dynamics in the rat testis. Biology of Reproduction 70 945-964. (https://doi.org/10.1095/ biolreprod.103.023606)

Sorokin S 1962 Centrioles and the formation of rudimentary cilia by fibroblasts and smooth muscle cells. Journal of Cell Biology 15 363-377. (https://doi.org/10.1083/jcb.15.2.363)

Spektor A, Tsang WY, Khoo D \& Dynlacht BD 2007 Cep97 and CP110 suppress a cilia assembly program. Cell 130 678-690. (https://doi. org/10.1016/j.cell.2007.06.027)

Stanton PG 2016 Regulation of the blood-testis barrier. Seminars in Cell and Developmental Biology 59 166-173. (https://doi.org/10.1016/j. semcdb.2016.06.018)

Steger K \& Wrobel K-H 1994 Immunohistochemical demonstration of cytoskeletal proteins in the ovine testis during postnatal development. Anatomy and Embryology 189 521-530. (https://doi.org/10.1007/ BF00186825)
Subramanian R \& Kapoor TM 2012 Building complexity: insights into selforganized assembly of microtubule-based architectures. Developmental Cell 23 874-885. (https://doi.org/10.1016/j.devcel.2012.10.011)

Sugino Y, Ichioka K, Soda T, Ihara M, Kinoshita M, Ogawa O \& Nishiyama H 2008 Septins as diagnostic markers for a subset of human asthenozoospermia. Journal of Urology 180 2706-2709. (https://doi. org/10.1016/j.juro.2008.08.005)

Summers KE \& Gibbons I 1971 Adenosine triphosphate-induced sliding of tubules in trypsin-treated flagella of sea-urchin sperm. PNAS $\mathbf{6 8}$ 3092-3096. (https://doi.org/10.1073/pnas.68.12.3092)

Szeverenyi I, Cassidy AJ, Chung CW, Lee BT, Common JE, Ogg SC, Chen H, Sim SY, Goh WL, Ng KW et al. 2008 The Human Intermediate Filament Database: comprehensive information on a gene family involved in many human diseases. Human Mutation 29 351-360. (https://doi. org/10.1002/humu.20652)

Tachibana M, Terada Y, Murakawa H, Murakami T, Yaegashi N \& Okamura K 2005 Dynamic changes in the cytoskeleton during human spermiogenesis. Fertility and Sterility 84 1241-1248. (https://doi. org/10.1016/j.fertnstert.2005.06.015)

Tame M, Raaijmakers J, Van Den Broek B, Lindqvist A, Jalink K \& Medema RH 2014 Astral microtubules control redistribution of dynein at the cell cortex to facilitate spindle positioning. Cell Cycle 13 1162-1170. (https://doi.org/10.4161/cc.28031)

Tanos BE, Yang H-J, Soni R, Wang W-J, Macaluso FP, Asara JM \& Tsou M-FB 2013 Centriole distal appendages promote membrane docking, leading to cilia initiation. Genes and Development 27 163-168. (https://doi. org/10.1101/gad.207043.112)

Taschner M \& Lorentzen E 2016 The intraflagellar transport machinery. Cold Spring Harbor Perspectives in Biology 8 a028092. (https://doi. org/10.1101/cshperspect.a028092)

Terman JR \& Kashina A 2013 Post-translational modification and regulation of actin. Current Opinion in Cell Biology 25 30-38. (https:// doi.org/10.1016/j.ceb.2012.10.009)

Vaid KS, Guttman JA, Singaraja RR \& Vogl AW 2007 A kinesin is present at unique sertoli/spermatid adherens junctions in rat and mouse testes. Biology of Reproduction 77 1037-1048. (https://doi.org/10.1095/ biolreprod.107.063735)

Valadares NF, D' Muniz Pereira H, Ulian Araujo AP \& Garratt RC 2017 Septin structure and filament assembly. Biophysical Reviews 9 481-500. (https://doi.org/10.1007/s12551-017-0320-4)

Vogl AW 1990 Distribution and function of organized concentrations of actin filaments in mammalian spermatogenic cells and Sertoli cells. International Review of Cytology 119 1-56.

Vogl A \& Soucy L 1985 Arrangement and possible function of actin filament bundles in ectoplasmic specializations of ground squirrel Sertoli cells. Journal of Cell Biology 100 814-825. (https://doi.org/10.1083/ jcb.100.3.814)

Vogl A, Linck R \& Dym M 1983 Colchicine-induced changes in the cytoskeleton of the golden-mantled ground squirrel (Spermophilus lateralis) Sertoli cells. American Journal of Anatomy 168 99-108. (https:// doi.org/10.1002/aja.1001680110)

Vogl A, Weis M \& Pfeiffer D 1995 The perinuclear centriole-containing centrosome is not the major microtubule organizing center in Sertoli cells. European Journal of Cell Biology 66 165-179.

Vogl A, Colucciguyon E \& Babinet C 1996 Vimentin intermediate filaments are not necessary for the development of a normal differentiated phenotype by mature Sertoli cells. Molecular Biology of the Cell 3227.

Vogl AW, Vaid KS \& Guttman JA 2008 The Sertoli cell cytoskeleton. Molecular Mechanisms in Spermatogenesis 636 186-211. (https://doi. org/10.1007/978-0-387-09597-4_11)

Vogl AW, Du M, Wang XY \& J'nelle SY 2014 Novel clathrin/actinbased endocytic machinery associated with junction turnover in the seminiferous epithelium. Seminars in Cell and Developmental Biology 30 55-64. (https://doi.org/10.1016/j.semcdb.2013.11.002)

Webster DR, Gundersen GG, Bulinski JC \& Borisy GG 1987 Differential turnover of tyrosinated and detyrosinated microtubules. PNAS $\mathbf{8 4}$ 9040-9044. (https://doi.org/10.1073/pnas.84.24.9040)

Wei Y-L \& Yang W-X 2018 The acroframosome-acroplaxome-manchette axis may function in sperm head shaping and male fertility. Gene $\mathbf{6 6 0}$ 28-40. (https://doi.org/10.1016/j.gene.2018.03.059) 
Welch JE \& O'Rand MG 1985 Identification and distribution of actin in spermatogenic cells and spermatozoa of the rabbit. Developmental Biology 109 411-417. (https://doi.org/10.1016/0012-1606(85)90467-1)

Wenz JR \& Hess RA 1998 Characterization of stage-specific tyrosinated $\alpha$-tubulin immunoperoxidase staining patterns in Sertoli cells of rat seminiferous tubules by light microscopic image analysis. Tissue and Cell 30 492-501. (https://doi.org/10.1016/S0040-8166(98)80028-1)

Werner ME, Hwang P, Huisman F, Taborek P, Clare CY \& Mitchell BJ 2011 Actin and microtubules drive differential aspects of planar cell polarity in multiciliated cells. Journal of Cell Biology 195 19-26. (https://doi. org/10.1083/jcb.201106110)

Wittmann T, Hyman A \& Desai A 2001 The spindle: a dynamic assembly of microtubules and motors. Nature Cell Biology 3 E28. (https://doi. org/10.1038/35050669)

Wu C-T, Chen H-Y \& Tang TK 2018 Myosin-Va is required for preciliary vesicle transportation to the mother centriole during ciliogenesis. Nature Cell Biology 20 175-185. (https://doi.org/10.1038/s41556-017-0018-7)

Xu J, Wan P, Wang M, Zhang J, Gao X, Hu B, Han J, Chen L, Sun K \& Wu J 2015 AIP1-mediated actin disassembly is required for postnatal germ cell migration and spermatogonial stem cell niche establishment. Cell Death and Disease 6 e1818. (https://doi.org/10.1038/cddis.2015.182)

Yang W-X \& Sperry AO 2003 C-terminal kinesin motor KIFC1 participates in acrosome biogenesis and vesicle transport. Biology of Reproduction 69 1719-1729. (https://doi.org/10.1095/biolreprod.102.014878)

Yao P-L, Lin Y-C \& Richburg JH 2010 Mono-(2-ethylhexyl) phthalate-induced disruption of junctional complexes in the seminiferous epithelium of the rodent testis is mediated by MMP2. Biology of Reproduction $\mathbf{8 2}$ 516-527. (https://doi.org/10.1095/biolreprod.109.080374)

Ye X, Zeng H, Ning G, Reiter JF \& Liu A 2014 C2cd3 is critical for centriolar distal appendage assembly and ciliary vesicle docking in mammals. PNAS 111 2164-2169. (https://doi.org/10.1073/pnas.1318737111)

Yeh C-H, Kuo P-L, Wang Y-Y, Wu Y-Y, Chen M-F, Lin D-Y, Lai T-H, Chiang HS \& Lin Y-H 2015 SEPT12/SPAG4/LAMINB1 complexes are required for maintaining the integrity of the nuclear envelope in postmeiotic male germ cells. PLoS ONE 10 e0120722. (https://doi.org/10.1371/journal. pone.0120722)

Yoshida T, Ioshii SO, Imanaka-Yoshida K \& Izutsu K 1994 Association of cytoplasmic dynein with manchette microtubules and spermatid nuclear envelope during spermiogenesis in rats. Journal of Cell Science $\mathbf{1 0 7}$ 625-633.

Young JS, Guttman JA, Vaid KS \& Vogl AW 2009 Tubulobulbar complexes are intercellular podosome-like structures that internalize intact intercellular junctions during epithelial remodeling events in the rat testis. Seminars in Cell and Developmental Biology 80 162-174. (https:// doi.org/10.1095/biolreprod.108.070623)

Young JS, De Asis M, Guttman J \& Vogl AW 2012 Cortactin depletion results in short tubulobulbar complexes and spermiation failure in rat testes. Biology Open 1 1069-1077. (https://doi.org/10.1242/bio.20122519)
Zhang X, Xu R, Zhu B, Yang X, Ding X, Duan S, Xu T, Zhuang Y \& Han M 2007 Syne- 1 and Syne-2 play crucial roles in myonuclear anchorage and motor neuron innervation. Development 134 901-908. (https://doi. org/10.1242/dev.02783)

Zhang Y, Liu H, Li W, Zhang Z, Shang X, Zhang D, Li Y, Zhang S, Liu J \& Hess RA 2017a Intraflagellar transporter protein (IFT27), an IFT25 binding partner, is essential for male fertility and spermiogenesis in mice. Developmental Biology 432 125-139. (https://doi.org/10.1016/j. ydbio.2017.09.023)

Zhang Y, Liu H, Li W, Zhang Z, Zhang S, Teves ME, Stevens C, Foster JA, Campbell GE \& Windle JJ 2017b Intraflagellar transporter protein 140 (IFT140), a component of IFT-A complex, is essential for male fertility and spermiogenesis in mice. Cytoskeleton 75 70-84. (https://doi. org $/ 10.1002 / \mathrm{cm} .21427$ )

Zhang Z, Shen X, Gude DR, Wilkinson BM, Justice MJ, Flickinger CJ, Herr JC, Eddy EM \& Strauss JF 2009 MEIG1 is essential for spermiogenesis in mice. PNAS 106 17055-17060. (https://doi. org/10.1073/pnas.0906414106)

Zhang Y, Ou Y, Cheng M, Shojaei Saadi H, Thundathil JC \& Van Der Hoorn FA 2012 KLC3 is involved in sperm tail midpiece formation and sperm function. Developmental Biology 366 101-110. (https://doi. org/10.1016/j.ydbio.2012.04.026)

Zhang Z, Li W, Zhang Y, Zhang L, Teves M, Liu H, Liu J, Strauss J, Pazour G \& Foster J 2016 Dual functions of Intraflagellar Transport Protein IFT20 in spermiogenesis: formation of sperm flagella and removal of cytoplasm by autophagy. bioRxiv 051219. (https://doi.org/10.1101/051219)

Zhi E, Li P, Chen H, Xu P, Zhu X, Zhu Z, He Z \& Li Z 2016 Decreased expression of KIFC1 in human testes with globozoospermic defects. Genes 7 75. (https://doi.org/10.3390/genes7100075)

Zhou J, Du Y-R, Qin W-H, Hu Y-G, Huang Y-N, Bao L, Han D, Mansouri A \& Xu G-L 2009 RIM-BP3 is a manchette-associated protein essential for spermiogenesis. Development 136 373-382. (https://doi.org/10.1242/ dev.030858)

Zhu F, Liu C, Wang F, Yang X, Zhang J, Wu H, Zhang Z, He X, Zhang Z, Zhou $\mathbf{P}$ et al. 2018 Mutations in PMFBP1 cause acephalic spermatozoa syndrome. American Journal of Human Genetics 103 188-199. (https:// doi.org/10.1016/j.ajhg.2018.06.010)

Received 28 August 2018

First decision 22 October 2018

Revised manuscript received 27 November 2018

Accepted 21 December 2018 